7-15-1996

\title{
Simulation of annual plankton productivity cycle in the Black Sea by a one-dimensional physical-biological model
}

\author{
Temel Oguz \\ Institute of Marine Sciences, Middle East Technical University \\ Hugh Ducklow \\ Virginia Institute of Marine Science \\ Paola Malanotte-Rizzoli \\ Massachusetts Institute of Technology \\ Nikolai P. Nezlin \\ p. p. Shirshov Institute of Oceanology, Russian Academy of Science \\ Umit Unluata \\ Institute of Marine Sciences, Middle East Technical University
}

Follow this and additional works at: https://scholarworks.wm.edu/vimsarticles

Part of the Marine Biology Commons

\section{Recommended Citation}

Oguz, Temel; Ducklow, Hugh; Malanotte-Rizzoli, Paola; Nezlin, Nikolai P.; and Unluata, Umit, "Simulation of annual plankton productivity cycle in the Black Sea by a one-dimensional physical-biological model" (1996). VIMS Articles. 292.

https://scholarworks.wm.edu/vimsarticles/292

This Article is brought to you for free and open access by W\&M ScholarWorks. It has been accepted for inclusion in VIMS Articles by an authorized administrator of W\&M ScholarWorks. For more information, please contact scholarworks@wm.edu. 


\title{
Simulation of annual plankton productivity cycle in the Black Sea by a one-dimensional physical-biological model
}

\author{
Temel Oguz,, ${ }^{1}$ Hugh Ducklow, ${ }^{2}$ Paola Malanotte-Rizzoli, ${ }^{3}$ Suleyman Tugrul, ${ }^{1}$ \\ Nikolai P. Nezlin, ${ }^{4}$ and Umit Unluata ${ }^{1}$
}

\begin{abstract}
The annual cycle of the plankton dynamics in the central Black Sea is studied by a one-dimensional vertically resolved physical-biological upper ocean model, coupled with the Mellor-Yamada level 2.5 turbulence closure scheme. The biological model involves interactions between the inorganic nitrogen (nitrate, ammonium), phytoplankton and herbivorous zooplankton biomasses, and detritus. Given a knowledge of physical forcing, the model simulates main observed seasonal and vertical characteristic features, in particular, formation of the cold intermediate water mass and yearly evolution of the upper layer stratification, the annual cycle of production with the fall and the spring blooms, and the subsurface phytoplankton maximum layer in summer, as well as realistic patterns of particulate organic carbon and nitrogen. The computed seasonal cycles of the chlorophyll and primary production distributions over the euphotic layer compare reasonably well with the data. Initiation of the spring bloom is shown to be critically dependent on the water column stability. It commences as soon as the convective mixing process weakens and before the seasonal stratification of surface waters begins to develop. It is followed by a weaker phytoplankton production at the time of establishment of the seasonal thermocline in April. While summer nutrient concentrations in the mixed layer are low enough to limit production, the layer between the thermocline and the base of the euphotic zone provides sufficient light and nutrient to support subsurface phytoplankton development. The autumn bloom takes place some time between October and December depending on environmental conditions. In the case of weaker grazing pressure to control the growth rate, the autumn bloom shifts to December-January and emerges as the winter bloom or, in some cases, is connected with the spring bloom to form one unified continuous bloom structure during the January-March period. These bloom structures are similar to the year-to-year variabilities present in the data.
\end{abstract}

\section{Introduction}

The Black Sea, once recognized by its rich biodiversity and abundant marine life, has been subject to drastic ecological changes during the last 2 decades. Introduction of large volumes of anthropogenic nutrient and contaminant loads from the Danube has been coupled with the massive growth of the medusa Auralia aurita and a newcomer ctenophore, Mnemiopsis leidii. These factors together with the overexploitation of fish resources have affected all components of the ecosystem [Mee, 1992]. The present state of the Black Sea ecosystem reflects severe degradation, dramatic decrease of biodiversity and fish stocks in the entire sea [Kideys, 1994], and near collapse of the ecosystem in the northwestern shelf and the Sea of Azov. In highly polluted shallow coastal regions of the northwestern shelf, red tides and mass mortality of benthic organ-

\footnotetext{
${ }^{1}$ Institute of Marine Sciences, Middle East Technical University, Erdemli, Icel, Turkey.

${ }^{2}$ Virginia Institute of Marine Sciences, The College of William and Mary, Gloucester Point, Virginia.

${ }^{3}$ Department of Earth, Atmospheric and Planetary Sciences, Massachusetts Institute of Technology, Cambridge.

${ }^{4}$ P. P. Shirshov Institute of Oceanology, Russian Academy of Sciences, Moscow, Russia.

Copyright 1996 by the American Geophysical Union.

Paper number $96 \mathrm{JC} 00831$.

0148-0227/96/96JC-00831\$09.00
}

isms due to the hypoxia/anoxia have currently become common phenomena [Zaitsev, 1992]. The effect of pollution is, however, relatively less severe in the central Black Sea because of its isolation from coastal and shelf waters by the Rim Current frontal zone [Sapozhnikov, 1991; Oguz et al., 1994].

In this study we examine the basic physical and biological processes controlling the seasonal cycle of the plankton productivity in the Black Sea. Using a series of numerical experiments, our aim is specifically to explore the conditions and the biological processes which may account for the observed bloom structures (see section 3). The model is restricted to two dimensions (time and depth) and is applied for the conditions appropriate to the central Black Sea. As compared with the northwestern shelf and the Rim Current frontal zone around the basin, horizontal variabilities and contributions of antropogenic inputs from rivers are less important, and this simplified approach might be justifiable for the interior of the sea. They are, however, crucially important processes which give rise to more complex and less predictable bloom dynamics in the coastal and shelf regions.

The present form of the model may be regarded as a first step to understand the first-order biological processes and to gain some experience and confidence for our future efforts on more sophisticated ecohydrodynamic modeling. At this stage we attempt, by the simplest possible means, to model the nitrogen-plankton dynamics using only primary producers and consumers and to understand the basic nutrient and material 
flows controlling the overall productivity in the Black Sea. The model consists of a single limiting nutrient (in the forms of nitrate and ammonium), single phytoplankton, and zooplankton groups and detritus. As suggested by the observations carried out elsewhere on similar conditions [e.g., Stramska and Dickey, 1994], a multilevel modeling approaç with a turbulence closure parameterization is chosen to resolve properly the upper ocean vertical structure and mixing process.

Section 2 provides a general description of both the physical and the biological models, the numerical techniques, and the initial and the boundary conditions appropriate to configure the models for the central Black Sea. Previous observations of plankton dynamics are discussed briefly in section 3. Model simulations and their implications as well as comparisons with the available observations are discussed in section 4. A summary and conclusions are given in section 5 .

\section{The Model}

The complete model includes the physical and biological submodels. In the absence of advective transports they are coupled through the parameterization of the vertical mixing process using the level 2.5 Mellor and Yamada [1982] turbulence closure scheme. While the model reveals fairly sophisticated mixed layer dynamics, its biology is intentionally kept simple to understand the basic interaction mechanisms. Models of this type have now widespread applications for different oceanic conditions [e.g., Varela et al., 1992; Radach and Moll, 1993; Sharples and Tett, 1994]. A recent application of a similar coupled physical-biological model to the Joint Global Ocean Flux Study (JGOFS) Bermuda Atlantic Time Series data [Doney et al., 1996] was very successful in reproducing seasonal cycles of the upper water column temperature field as well as of the chlorophyll and primary production.

\subsection{The Physical Model}

The physical model is the one-dimensional version of the Princeton Ocean Model [Blumberg and Mellor, 1987] and is similar to the one given by Stramska and Dickey [1994]. For a horizontally homogeneous, incompressible, Boussinesq and hydrostatic sea with no vertical water motion, the horizontal momentum equation is expressed as

$$
(\partial \mathbf{u} / \partial t)-f \hat{k} \times \mathbf{u}=(\partial / \partial z)\left[\left(K_{m}+\nu_{m}\right)(\partial \mathbf{u} / \partial z)\right]
$$

where $t$ is time, $z$ is the vertical coordinate, $u$ is the horizontal velocity of the mean flow with the components $(u, v), \hat{\mathbf{k}}$ is the unit vector in the vertical direction, $\partial$ denotes the partial differentiation, and $f$ is the Coriolis parameter. $K_{m}$ denotes the coefficient for the vertical turbulent diffusion of momentum, and $\nu_{m}$ represents its background value associated with internal wave mixing and other small-scale mixing processes. The vertical advective motion is neglected, for simplicity, although this assumption may be questionable with regards to the upward advective transport of nutrients in the cyclonic regions of the Black Sea.

The temperature $T$ and the salinity $S$ are determined from transport equations of the form

$$
\partial C / \partial t=(\partial / \partial z)\left[\left(K_{h}+\nu_{h}\right)(\partial C / \partial z)\right]
$$

where $C$ denotes either $T$ or $S, K_{h}$ is the coefficient for the vertical turbulent heat and salt diffusions, and $\nu_{h}$ is its background value. The solar irradiance which penetrates into the water column is not parameterized separately in the temperature equation, for simplicity. Its effect, together with other components of the total heat flux, is represented through the surface boundary condition given in (4). One implication of this simplification is to neglect a relatively minor effect of the feedback of the biological model on the evolution of the mixed layer depth and temperature via the attenuation of radiation by phytoplankton. The density is expressed as functions of the potential temperature, salinity, and pressure, $\rho=\rho(T, S, p)$, using a nonlinear equation of state [Mellor, 1990].

The vertical mixing coefficients are determined from

$$
\left(K_{m}, K_{h}\right)=\operatorname{lq}\left(S_{m}, S_{h}\right)
$$

where $l$ and $q$ denote the turbulent length scale and turbulent velocity, respectively. $S_{m}, S_{h}$ are the stability factors expressed algebraically as given by Mellor and Yamada [1982]. In the level 2.5 turbulence closure, $l$ and $q$ are computed from the turbulent kinetic energy, $\frac{1}{2} q^{2}$, and the turbulent macroscale equations. The vertical shear of the horizontal velocity and the vertical density gradient of the mean flow are used to express the turbulent buoyancy and shear productions in these equations. $K_{h}$ is assumed to represent also the eddy coefficient for vertical turbulent diffusion of the biological variables.

The equations (1) and (2) are subject to the following boundary conditions at the sea surface, $z=0$ :

$$
\begin{gathered}
\rho_{0} K_{m}(\partial u / \partial z, \partial v / \partial z)=\left(\tau_{s u}, \tau_{s v}\right) \\
K_{h}(\partial T / \partial z)=Q_{H} / \rho_{0} c_{p}, \\
S=S_{0}
\end{gathered}
$$

where $\tau_{s u}, \tau_{s v}$ are the wind stress components, $Q_{H}$ is the net surface heat flux, $S_{0}$ is the surface salinity, $\rho_{0}$ is the reference density, and $c_{p}$ is the specific heat of water. As shown in (6) the surface salinity is stipulated as the boundary condition in the salinity equation. This condition implies restoring the salinity in the top grid layer with an infinite restoring timescale. As compared with the flux boundary condition it leads to predicting a more realistic salinity structure, in better agreement with the observations during the year. The bottom of the model is taken at the 200-m depth corresponding to the base of the permanent pycnocline. No-stress, no-heat, and no-salt flux conditions are specified there.

The physical forcing functions are constructed from the climatology in order to be consistent with the data used in the biological model. As shown in the next section the composite diagrams for the yearly variations of the primary production and chlorophyll-a (see Figures $2 b$ and $2 c$ ), to our knowledge, are the only available time series data for the central Black Sea. Using real-time series data for the physical forcing functions therefore has no advantage except introducing some high-frequency variability which cannot be correlated with the biological system. The momentum and temperature equations are thus forced by the monthly varying wind stress and surface heat flux climatologies, respectively, given by Efimov and Timofeev [1990]. The magnitude of the wind stress, which is dominated by northerlies throughout the year, has the maximum and minimum values of 0.8 and $0.3 \mathrm{dyn}^{-2}$ in the winter and summer months, respectively. The climatological heat flux data are adjusted to make the net annual flux zero. It attains maximum cooling of $150 \mathrm{~W} \mathrm{~m}^{-2}$ during January and February, while the maximum heating of $\sim 200 \mathrm{~W} \mathrm{~m}^{-2}$ occurs during the June-July period. The monthly surface salinity val- 
Table 1. Model Parameters Used in the Numerical Experiments

\begin{tabular}{|c|c|c|}
\hline Parameter & Definition & Value \\
\hline$f$ & Coriolis parameter & $1 \times 10^{-4} \mathrm{~s}^{-1}$ \\
\hline$\nu_{m}, \nu_{h}, \nu_{b}$ & $\begin{array}{l}\text { background (molecular) value of kinematic } \\
\text { viscosity and diffusivity }\end{array}$ & $1 \times 10^{-6} \mathrm{~m}^{2} \mathrm{~s}^{-1}$ \\
\hline$g$ & gravitational acceleration & $9.81 \mathrm{~m} \mathrm{~s}^{-2}$ \\
\hline$\rho_{0}$ & reference density & $1000 \mathrm{~kg} \mathrm{~m}^{-3}$ \\
\hline & specific heat of water & $4 \times 10^{3} \mathrm{~J} \mathrm{~kg}^{-1} \mathrm{C}^{-1}$ \\
\hline$u_{g}, v_{g}$ & geostrophic velocity components & $0 . \mathrm{m} \mathrm{s}^{-1}$ \\
\hline & von Karman constant & 0.4 \\
\hline$z_{0}$ & roughness length for the surface boundary layer & $0.01 \mathrm{~m}$ \\
\hline$\Delta t$ & time step & 1.0 hour \\
\hline$\sigma_{m}$ & maximum phytoplankton growth rate & $1.5 \mathrm{day}^{-1}$ \\
\hline$a$ & photosynthesis efficiency parameter & $0.01\left(\mathrm{~W} \mathrm{~m}^{-2}\right)^{-1}$ \\
\hline$k_{w}$ & $\begin{array}{l}\text { light extinction coefficient for photosynthetically } \\
\text { active irradiance (PAR) }\end{array}$ & $0.08 \mathrm{~m}^{-1}$ \\
\hline$k_{c}$ & phytoplankton self-shading coefficient & $0.07 \mathrm{~m}^{2}(\mathrm{mmol} \mathrm{N})^{-1}$ \\
\hline$R_{n}$ & nitrate half-saturation constant & $0.5 \mathrm{mmol} \mathrm{N} \mathrm{m}^{-3}$ \\
\hline$R_{a}^{\prime \prime}$ & ammonium half-saturation constant & $0.2 \mathrm{mmol} \mathrm{N} \mathrm{m}^{-3}$ \\
\hline$m_{p}$ & phytoplankton death rate & $0.04 \mathrm{day}^{-1}$ \\
\hline$r_{g}$ & herbivore maximum grazing rate & 0.8 day $^{-1}$ \\
\hline$R_{g}^{g}$ & herbivore half-saturation constant & $0.5 \mathrm{mmol} \mathrm{N} \mathrm{m}^{-3}$ \\
\hline$m_{h}$ & herbivore death rate & 0.04 day $^{-1}$ \\
\hline$\mu_{h}$ & herbivore excretion rate & $0.07 \mathrm{day}^{-1}$ \\
\hline$\gamma_{h}$ & herbivore assimilation efficiency & 0.75 \\
\hline$\varepsilon$ & detrital remineralization rate & 0.1 day $^{-1}$ \\
\hline $\mathbf{\Omega}$ & oxidation rate & $0.05 \mathrm{day}^{-1}$ \\
\hline$w_{s}$ & detrital sinking rate & $1.0 \mathrm{~m}$ day $^{-1}$ \\
\hline$P_{0}$ & initial phytoplankton concentration & $0.25 \mathrm{mmol} \mathrm{N} \mathrm{m}^{-3}$ \\
\hline$H_{0}$ & initial herbivore concentration & $0.05 \mathrm{mmol} \mathrm{N} \mathrm{m}^{-3}$ \\
\hline$C_{0}$ & initial herbivore concentration & $0.05 \mathrm{mmol} \mathrm{N} \mathrm{m}^{-3}$ \\
\hline$D_{0}$ & initial detritus concentration & $0.05 \mathrm{mmol} \mathrm{N} \mathrm{m}^{-3}$ \\
\hline$A_{0}$ & initial ammonium concentration & $0.05 \mathrm{mmol} \mathrm{N} \mathrm{m}^{-3}$ \\
\hline
\end{tabular}

ues are obtained from the climatological atlas of Altman et al. [1987]. It follows closely the seasonal trend of the heat flux and varies between the values of 18.1 parts per thousand (ppt) in the summer and $18.6 \mathrm{ppt}$ during the period of maximum cooling in winter. Monthly mean climatological values of these forcings are given in Table 2.

\subsection{The Biological Model}

The biological variables considered are the phytoplankton biomass $P$, the herbivorous zooplankton biomass $H$, and the pelagic detritus $D$, the nitrate $N$, and ammonium $\mathrm{A}$. Low nitrate to phosphate ratio in the layer below the euphotic zone implies nitrogen as the limiting nutrient for the primary productivity in the central Black Sea due to its intense utilization in the heterotrophic denitrification process [Sorokin, 1983]. The local changes of the biological variables are expressed by an equation of the form

$$
\partial B / \partial t=(\partial / \partial z)\left[\left(K_{h}+\nu_{h}\right)(\partial B / \partial z)\right]+F_{B}
$$

where $B$ represents any of the five biological variables in the model, $t$ is the time, $z$ is the vertical coordinate, and $\partial$ denotes the partial differentiation. $F_{B}$ represents the biological interaction terms expressed for the phytoplankton, herbivore, detritus, ammonium, and nitrate equations, respectively, as [e.g., Wroblewski, 1977; Fasham et al., 1990]

$$
\begin{gathered}
F_{P}=\Phi(I, N, A) P-G(P) H-m_{p} P \\
F_{H}=\gamma G(P) H-m_{h} H-\mu_{h} H \\
F_{D}=(1-\gamma) G(P) H+m_{p} P+m_{h} H-\varepsilon D+w_{s}(\partial D / \partial z) \\
F_{A}=-\Phi_{a}(I, A) P+\mu_{h} H+\varepsilon D-\Omega A
\end{gathered}
$$

$$
F_{N}=-\Phi_{n}(I, N) P+\Omega A
$$

where the definitions of parameters and their values used in the main experiment are given in Table 1. The functions $\Phi(I$, $N, A)$ and $G(P)$ denote the phytoplankton growth and grazing by zooplankton, $m_{p}$ is the phytoplankton mortality rate, $m_{h}$ represents losses due to dead zooplankton leading to detritus production, $\mu$ is the rate of zooplankton excretion in the form of nitrogen, $\gamma$ is the assimilation efficiency of zooplankton grazing on phytoplankton, $\varepsilon$ is the detrital remineralization rate, $\Omega$ is the ammonium oxidation rate, and $w_{s}$ denotes the downward sinking velocity of detritus.

The phytoplankton production process is parameterized in terms of the Liebig's law of the minimum which assumes either light or a nutrient, but not both, controls growth rate at any instant [e.g., de Baar, 1994]. The total production, $\Phi(I, N, A)$, is defined by

$$
\Phi(I, N, A)=\sigma_{m} \min \left[\alpha(I), \beta_{t}(N, A)\right]
$$

where min refers to the minimum of either $\alpha(I)$ or $\beta_{t}(N, A)$ representing the light limitation function and the total nitrogen limitation function of the phytoplankton uptake, respectively. Here $\beta_{t}(N, A)$ is given in the form

$$
\beta_{t}(N, A)=\beta_{n}(N)+\beta_{a}(A)
$$

with $\beta_{a}(A)$ and $\beta_{n}(N)$ signifying contributions of the ammonium and nitrate limitations, respectively. They are expressed by the Michaelis-Menten uptake formulation

$$
\begin{gathered}
\beta_{a}(A)=A /\left(R_{a}+A\right) \\
\beta_{n}(N)=N /\left(R_{n}+N\right) \exp (-\psi A)
\end{gathered}
$$


Table 2. Monthly Climatological Values of Forcings at the Central Days of Each Month

\begin{tabular}{|c|c|c|c|c|c|c|c|c|c|c|c|c|}
\hline Forcing & Jan. & Feb. & March & April & May & June & July & Aug. & Sept. & Oct. & Nov. & Dec. \\
\hline Heat flux, $\mathrm{W} \mathrm{m}^{-2}$ & 105 & 80 & 0 & -70 & -110 & -135 & -90 & -45 & 10 & 60 & 95 & 105 \\
\hline Salinity, ppt & 18.40 & 18.50 & 18.60 & 18.50 & 18.40 & 18.30 & 18.20 & 18.10 & 18.15 & 18.20 & 18.25 & 18.30 \\
\hline Wind stress, dyn $\mathrm{cm}^{-2}$ & 0.70 & 0.75 & 0.75 & 0.60 & 0.50 & 0.40 & 0.30 & 0.25 & 0.35 & 0.50 & 0.50 & 0.60 \\
\hline PAR, $\mathrm{W} \mathrm{m}^{-2}$ & 20 & 20 & 40 & 110 & 200 & 250 & 280 & 300 & 220 & 160 & 90 & 25 \\
\hline
\end{tabular}

where $R_{n}$ and $R_{a}$ are the half-saturation constants for nitrate and ammonium, respectively. The exponential term in (16) represents the inhibiting effect of ammonium concentration on nitrate uptake, with $\psi$ signifying the inhibition parameter [Wroblewski, 1977].

The individual contributions of the nitrate and ammonium uptakes to the phytoplankton production are represented by, respectively, [c.f. Varela et al., 1992]

$$
\begin{gathered}
\Phi_{n}(I, N)=\sigma_{m} \min \left[\alpha(I), \beta_{t}(N, A)\right]\left(\beta_{n} / \beta_{t}\right) \\
\Phi_{a}(I, A)=\sigma_{m} \min \left[\alpha(I), \beta_{t}(N, A)\right]\left(\beta_{a} / \beta_{t}\right)
\end{gathered}
$$

The light limitation is parameterized according to Jassby and Platt [1976] by

$$
\begin{gathered}
\alpha(I)=\tanh [a I(z, t)] \\
I(z, t)=I_{s} \exp \left[-\left(k_{w}+k_{c} P\right) z\right]
\end{gathered}
$$

where $a$ denotes photosynthesis efficiency parameter controlling the slope of $\alpha(I)$ versus the irradiance curve at low values of the photosynthetically active irradiance (PAR). $I_{s}$ denotes the surface intensity of the PAR taken as the half of the climatological incoming solar radiation from the data by Efimov and Timofeev [1990]. It varies between a minimum value of $20 \mathrm{~W} \mathrm{~m}^{-2}$ during winter and a maximum value of 300 $\mathrm{W} \mathrm{m} \mathrm{m}^{-2}$ in summer (see Table 2). Here $k_{w}$ is the light attenuation coefficient due to sea water, and $k_{c}$ is the phytoplankton self-shading coefficient. In the above formulation, $k_{w}$ and $k_{c}$ are taken to be constant with depth. The daily variation of the light irradiance and hence the phytoplankton growth are neglected since the biological processes we consider have timescales much longer than a day.

The zooplankton grazing ability is represented by the Michaelis-Menten formulation

$$
G(P)=\sigma_{g} P /\left(R_{g}+P\right)
$$

where $\sigma_{g}$ is the maximum ingestion rate and $R_{g}$ is the halfsaturation ratio for the zooplankton grazing.

No-flux conditions $\left[\left(K_{h}+\nu_{h}\right)(\partial B / \partial z)=0\right]$ are specified both at the surface and the bottom. For the case of detritus equation the surface boundary condition is modified to include the contribution of downward sinking flux so that $\left(K_{h}+\nu_{h}\right)$ $(\partial D / \partial z)+w_{s} D=0$. The same condition is also prescribed at the lower boundary of the model which is taken at $200-\mathrm{m}$ depth, well below the euphotic zone comprising only the upper 40-50 m. Considering our choice of relatively low sinking rate $\left(w_{s}=1.0 \mathrm{~m} \mathrm{day}^{-1}\right)$ (see Table 1 ), the advantage of locating the bottom boundary at considerable distance away from the euphotic layer is to allow the complete remineralization of the detrital material until it reaches the lower boundary of the model. As seen from (7) to (12) the vertically integrated biological model is fully conservative. The state of the system at time $t$ is governed by its evolution through the internal dynamical processes from the specified initial conditions.

\subsection{Initial Data and Numerical Techniques}

The model is initialized with the stably stratified upper ocean temperature and salinity profiles representative of the autumn climatological conditions for the interior part of the Black Sea. Major stratification characteristics of these profiles include a permanent pycnocline around $100 \mathrm{~m}$, across which there is more than $3 \mathrm{~kg} \mathrm{~m}^{-3}$ density difference, a shallow ( $\sim 15$ m) surface mixed layer overlying a strong and narrow thermocline, and the cold intermediate layer (CIL) identified with temperature values less than $8^{\circ} \mathrm{C}$ residing between the seasonal thermocline and the permanent pycnocline. The upper layer salinity structure undergoes gradual changes from $\sim 18.35$ ppt at the base of the mixed layer to $\sim 20.5 \mathrm{ppt}$ near the base of the pycnocline at $\sim 150 \mathrm{~m}$. This strong salinity variations is the main cause of strong density stratification which keeps the halocline-pycnocline zone always stable against destabilizing effect of the temperature inversion layer of the CIL waters.

The initial nitrate profile (Figure 1) is similar to those shown by Basturk et al. [1994]. It reveals a gradual increase of the surface concentrations of $0.2 \mathrm{mmol} \mathrm{m}^{-3}$ to a subsurface maximum of about $6 \mathrm{mmol} \mathrm{m}^{-3}$ at the depth of $\sim 60 \mathrm{~m}$. The nitrate concentration then diminishes sharply to trace levels $(<0.10$ mmol m${ }^{-3}$ ) near the $\mathrm{H}_{2} \mathrm{~S}$ boundary where the bacteria utilize the nitrate ions to oxidize the organic matter sinking from the productive surface layer. The presence of a narrow subsurface maximum, followed by a sharp reduction toward the $\mathrm{H}_{2} \mathrm{~S}$ interface, constitutes the major difference of the Black Sea vertical nitrate structure from those observed in the oxygenated basins. Initial phytoplankton, zooplankton, detritus, and ammonium distributions are taken vertically uniform within the euphotic layer.

The model equations are solved using the finite difference procedure described by Mellor [1990]. A total of 51 vertical levels is used for the water column of $200-\mathrm{m}$ depth. The grid

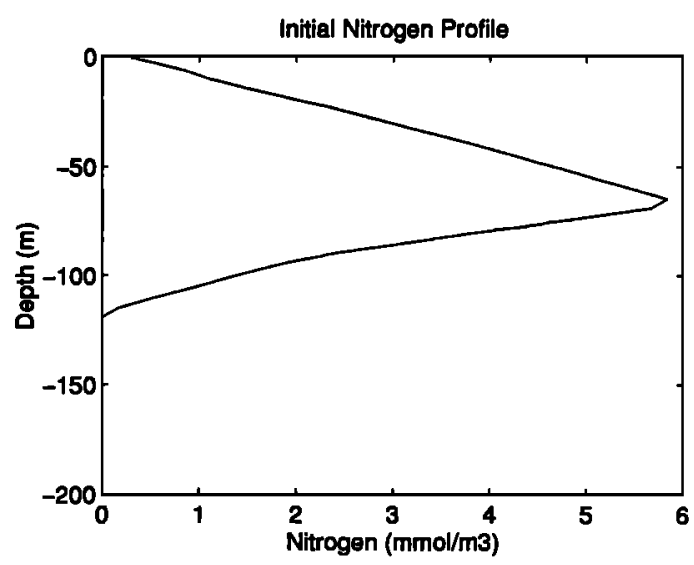

Figure 1. Vertical nitrate profile (micromoles of $\mathbf{N}$ per cubic meter) used as the initial condition in the model. 
spacing is compressed slightly toward the surface to increase the resolution within the uppermost levels. The numerical scheme is implicit to avoid computational instabilities due to small grid spacing. The separation of solutions associated with the leapfrog time differencing is avoided by using a time filter. A time step of 15 minutes is used in the numerical integration of the equations.

First, the physical model is integrated for 5 years. An equilibrium state with repeating yearly cycle of the dynamics is achieved after 3 years of integration in response to the imposed external forcings and to the internal processes in the system. Using the results of the fifth year of the physical model, the biological model is then integrated for 4 years to obtain repetitive yearly cycles of the biological variables. The quantitative measure of testing the attainment of the cyclical state is to check whether the depth integrated total nitrogen content, $\mathbf{N}_{T}(=\mathbf{N}+\mathbf{A}+\mathbf{P}+\mathbf{H}+\mathrm{D})$, approaches a constant value over the annual cycle.

\section{Observations}

Using findings from the light penetration measurements, values of the total extinction coefficient are estimated in the range from 0.10 to $0.22 \mathrm{~m}^{-1}$ within the deep part of the Black Sea, depending on the local conditions at the time of measurements [Vidal, 1995]. These estimates are consistent with those obtained by the long-term monthly average secchi disk data [Vladimirov et al., 1996]. The secchi disk depths vary from about $11 \mathrm{~m}$ during March to about $19 \mathrm{~m}$ during the summer months. Using the conversion factor of 2.7 , these secchi disk data imply the $1 \%$ light penetration depth of about 30 and the value of the total extinction coefficient of $\sim 0.20 \mathrm{~m}^{-1}$ during the spring bloom period. The corresponding values are $50 \mathrm{~m}$ and $\sim 0.10 \mathrm{~m}^{-1}$ during the summer months. The choices of $k_{w}=0.08 \mathrm{~m}^{-1}$ and $k_{c}=0.07 \mathrm{~m}^{2} \mathrm{mmol}^{-1} \mathrm{~N}$ in the model provide yearly variations of the total extinction coefficient $(k=$ $k_{w}+k_{c} P$ ) consistent with these estimates.

The primary productivity and chlorophyll-a annual time series data indicate that the Black Sea exhibits characteristics of temperate basins with apparently two peaks observed during

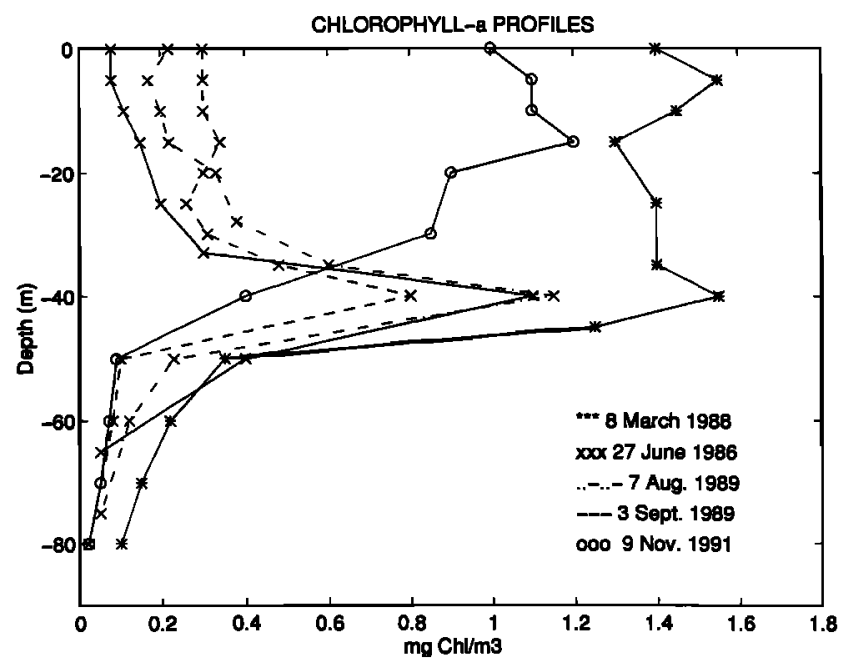

Figure 2a. Vertical profiles of chlorophyll-a (milligrams of Chl per cubic meter) measured within the central Black Sea at different seasons. The data are from Vedernikov and Demidov [1993].

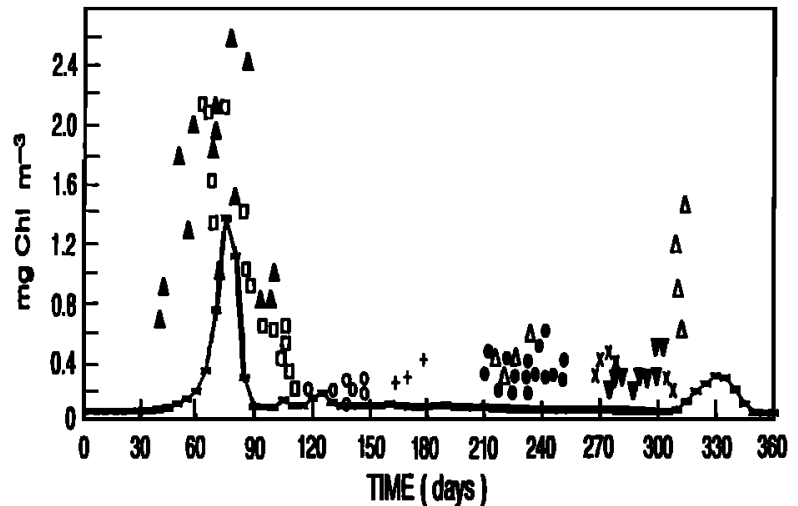

Figure 2b. A composite picture of the euphotic layer average chlorophyll concentrations (milligrams of Chl per cubic meter) within the year compiled from different data sources (open and solid triangles, 1991; solid circles, 1989; open squares, 1988; plusses, 1986; crosses, 1985; open circles, 1984; solid reverse triangles, 1978). The data are redrawn from Vedernikov and Demidov [1993]. The continuous line shows the model predicted chlorophyll concentration.

early spring and fall [Sorokin, 1983; Vedernikov and Demidov, 1993]. When the water column is thermally stratified during the summer season, nutrient and phytoplankton levels are low within the shallow mixed layer of $\sim 10-15 \mathrm{~m}$. Below the mixed layer, toward the base of the euphotic layer, however, there exists a subsurface chlorophyll maximum (Figure 2a). This is accompanied by relatively higher nitrate concentrations. During the autumn season, at the time of destratification of the water column, nitrate flux to the surface waters is enhanced across the thermocline. This is taken up by phytoplankton in the euphotic zone, leading to a phytoplankton bloom of mainly coccoliths with 2-3 weeks duration in October, November, and December, depending on the local atmospheric and biochemical conditions. The spring bloom, dominated by diatoms, occurs at the time of rapid stratification of the water column (typically March) and is accompanied by considerable decrease of near-surface nutrient concentrations. The March and November profiles given in Figure 2a represent the conditions of vertically uniform, relatively higher chlorophyll concentrations associated with these blooms.

In Figures $2 \mathrm{~b}$ and $2 \mathrm{c}$ we display the annual cycle of chloro-

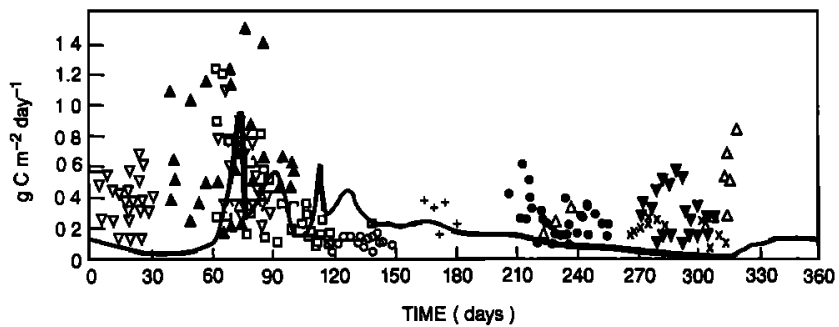

Figure 2c. A composite picture of the euphotic layer integrated primary production distribution (milligrams of $C$ per square meter per day) within the year compiled from different data sources (open and solid triangles, 1991; solid circles, 1989; open squares, 1988; plusses, 1986; crosses, 1985; open circles, 1984; solid and open reverse triangles, 1978). The data are redrawn from Vedernikov and Demidov [1993]. The continuous line shows the model predicted primary production. 

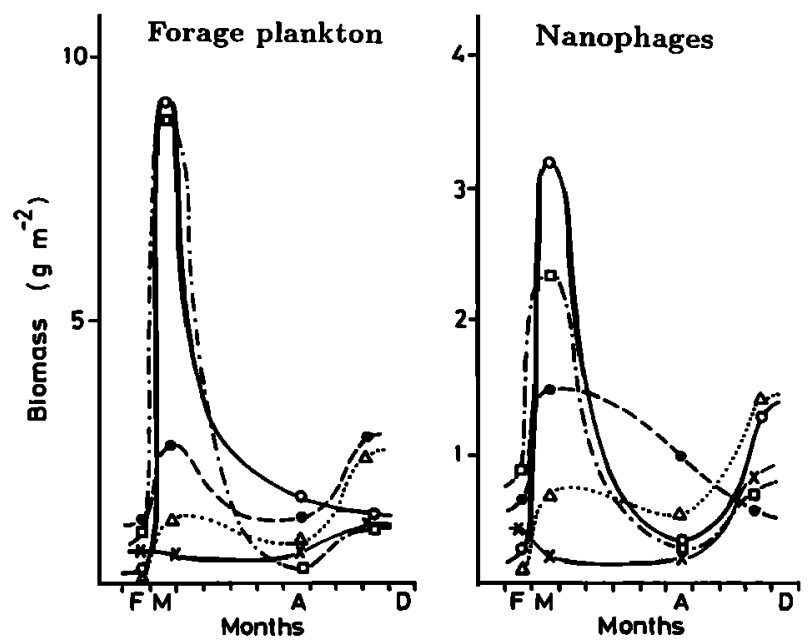

Sagitta

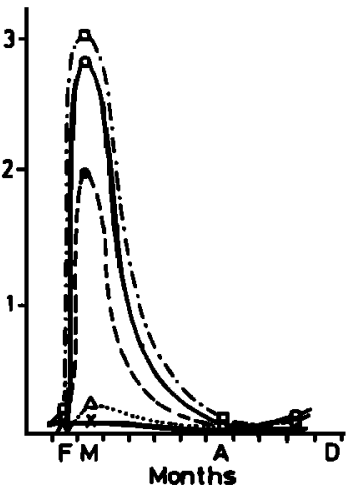

Figure 2d. Seasonal variations of some mesozooplankton biomass at different locations in the central Black Sea during 1991 [after Vinogradov and Shushkina, 1992]. F, February; M, March; A, August; D, December. Symbols as in Figures $2 b$.

phyll-a and primary productivity distributions constructed by combining the observations carried out within the central basin during the last decade [Vedernikov and Demidov, 1993], the continuous lines giving the corresponding model predictions. One important implication of Figures $2 \mathrm{~b}$ and $2 \mathrm{c}$ is the presence of year-to-year variabilities in the productivity cycle. They show considerable spatial variabilities as well, even within the interior basin away from the coastal effects and the Rim Current frontal zone. The 1991 observations, shown by solid triangles in the February-March period and open triangles in November in Figures $2 b$ and $2 c$, suggest existence of the two blooms during November and either February or March depending on the regional conditions. The peaks in the mesozooplankton data given in Figure 2d provide an independent support for the blooms; these peaks wouldn't exist without previous phytoplankton blooming. In 1988 observations, presented by the open squares in the figures, the spring bloom occurs again in March, but the autumn bloom is shifted to January. Although no data points are seen here for February 1988, the original data reported by Finenko and Krupatkina [1993] show these two bloom periods are separated by the conditions of low productivity.

The data therefore seem to suggest two main autumn-winter plankton structures in the central Black Sea. The first is the regular two-bloom structure with the peaks in November and March. The second is the shift of the autumn bloom toward December-January, while the spring bloom occurs in March. It is also reported that, in some cases, the spring bloom may take place earlier in February as generally observed in mild winters. Or the winter bloom continues in February and is combined with the spring one to develop a single relatively long bloom season for the entire winter [Vedernikov and Demidov, 1993]. The regional oceanographic conditions during December and February seem to be critical and to control realization of any one of them.

\section{Results and Discussion}

\subsection{Upper Layer Physical Structure}

The yearly response of the upper layer physical structure to the climatological atmospheric forcing functions is shown in Figures $3 a$ and $3 b$ in the forms of series of temperature and sigma-theta profiles at different times of the year. The autumn period corresponds to the preconditioning and initial cooling phase with the mixed layer depth of $25 \mathrm{~m}$ and temperature and density values of $\sim 11^{\circ} \mathrm{C}$ and $13.7 \mathrm{~kg} \mathrm{~m}^{-3}$ in mid-November.
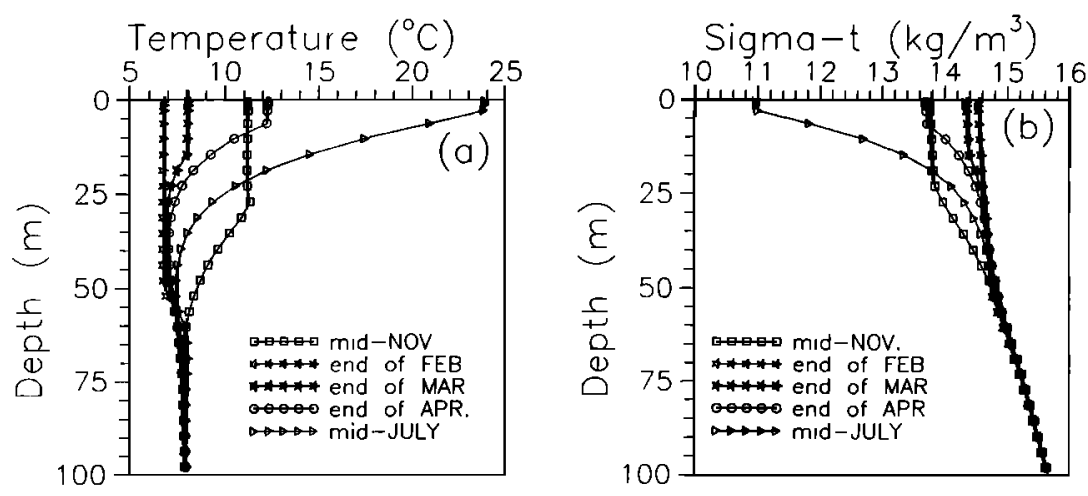

Figure 3. Computed depth profiles of (a) temperature (degrees Celsius), (b) sigma-theta (kilograms per cubic meter), and (c) vertical eddy diffusivity (square centimeters per second) at different times of the year. 
This is followed by the deeper penetration of the mixed layer and subsequent cold water mass formation associated with the stronger winter cooling during January and February. The convective mixing attains its maximum intensity toward the end of February, generating the mixed layer of about $60 \mathrm{~m}$ with characteristic temperature of $\sim 6.8^{\circ} \mathrm{C}$ and density of $\sim 14.5 \mathrm{~kg} \mathrm{~m}^{-3}$. Deeper penetration of the convective mixed layer does not take place due to the freshness of the surface waters $(\sim 18.0-$ $18.5 \mathrm{ppt}$ ) overlying the shallow permanent pycnocline. We note that the winter mixed layer temperature computed by the model by means of climatological, smoothed heat flux data is somewhat warmer than those measured. The observed winter temperature and density values of $\sim 6.0^{\circ} \mathrm{C}$ and $\sim 14.7 \mathrm{~kg} \mathrm{~m}^{-3}$ are reported by Ovchinnikov and Popov [1987].

During the spring transition period the water column warms up gradually, developing a sharp seasonal thermocline system at the base of the shallow mixed layer of $\sim 10 \mathrm{~m}$ later in the summer months. The maximum surface temperature and the corresponding minimum surface density are $\sim 24^{\circ} \mathrm{C}$ and $\sim 11$ $\mathrm{kg} \mathrm{m}^{-3}$, respectively, in July. The cold intermediate iayer defined by the temperature values less than $8^{\circ} \mathrm{C}$ is modified by its gradual warming and deepening toward the end of summer period.

The summer months of wind-induced, weak and shallow $(\sim 10 \mathrm{~m})$ mixed layer characteristics are reflected in the low values of eddy diffusivity, less than about $10 \mathrm{~cm}^{2} \mathrm{~s}^{-1}$ (Figure $3 c)$. The intensification of turbulent activity during the cooling cycle of the year is revealed by the 2-3 order of magnitude increase in the eddy diffusivity inside the convectively generated mixed layer. This period has the characteristic $K_{h}$ profile similar to those given by the November and February curves in Figure 3c. The mid-March profile exhibits an interesting transient mixing condition after weakening of the convective overturning mechanism but prior to the development of subsurface stratification below the mixed layer. These two mixing regimes are identified with the two distinct maxima in the $K_{h}$ profile, separated from each other by a transition zone of weak mixing. This narrow zone of low $K_{h}$ values coincides with the base of the mixed layer, as confirmed by the temperature and density profiles in Figures 3a and 3b. We emphasize here once again that the vertical mixing mechanism in the model is the entrainment process associated with the convective overturning. Having the relatively weak climatological wind stresses for most of the year, the wind-induced mixing mechanism does not play significant role on the surface layer physical structure.

The depth at which the turbulent kinetic energy tends to vanish and the vertical diffusion coefficient reduces to its background value provides a quantitative measure for the identification of the base of the mixed layer over the year. The annual distribution of the mixed layer depth computed from the model using this criterion and that obtained from the climatological data is shown in Figure 4a. The observed mixed layer distribution is taken by E. Ozsoy et al. (unpublished manuscript, 1995) and represents the mean climatological conditions with the standard deviations of $\pm 5 \mathrm{~m}$ during the summer and of $\pm 10 \mathrm{~m}$ during the rest of the year. We note from Figure $4 \mathrm{a}$ that the model distribution fits generally to the data during the spring and the summer seasons. The differences in the cooling period of the year are within the range of the variations present in the climatological data. Another model versus data comparison is given in Figure $4 b$ for the annual distribution of the surface temperature. The consistency of observed and computed mixed layer temperatures is particularly good during the

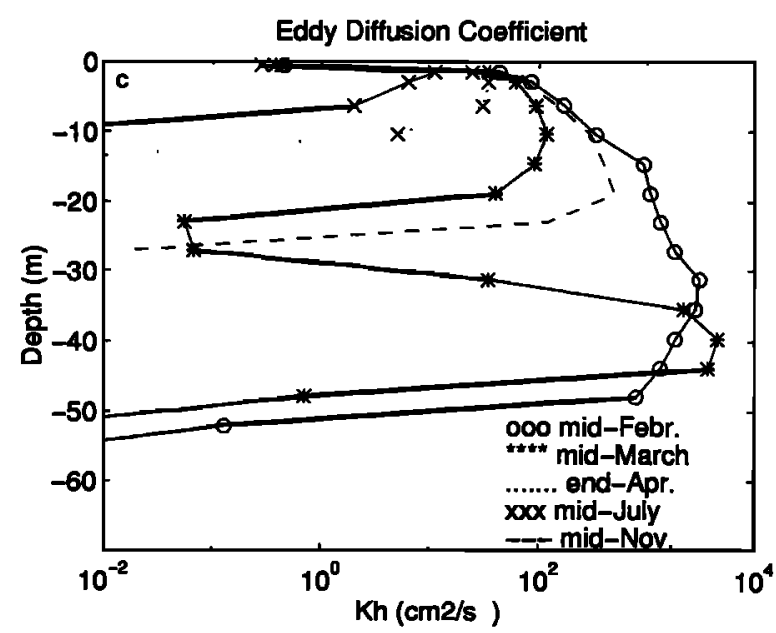

Figure 3. (continued)

winter and spring seasons. The model, on the other hand, underestimates the mixed layer temperatures during the transition period of late summer-early autumn by few degrees, as compared with the data given by Vedernikov and Demidov [1993]. The model temperatures, however, have a better agreement with the monthly averaged climatological data set of Altman et al. [1987] during this period [c.f. Oguz et al., 1992]. Furthermore, as noted earlier, the mixed layer temperature structure is decoupled from the biological system since the present formulation of the primary productivity does not include the temperature dependence. Thus the mixed layer physical structure does not play any role in the biological model, except its contribution to the vertical structure of the eddy diffusivity.

\subsection{Biological Structure of the Euphotic Zone}

Contrary to the more comforting parametric setting of the physical model, a successful simulation of the biological model requires a choice of 16 externally imposed parameters (see Table 1). Most of these parameters are hardly known from the observations. In fact, determination of the values of the rate constants from the measurements constitutes one of the primary objectives of the ongoing collaborative research efforts in the Black Sea community. In the present work the ranges of values of the parameters are chosen from the Black Sea literature [e.g., Lebedeva and Shuskina, 1994; Belyaev and Kundufarova, 1992; Krivenko and Lukjanova, 1994] as well as from other seas with similar pelagic ecosystems and upper layer physical characteristics (e.g., the Sea of Marmara [Tugrul and Morkoc, 1990], the North Sea [Radach and Moll, 1993], and the Baltic Sea [Savchuk and Wulff, 1993]; see also Fasham et al. [1993]). The set of parameters is then adjusted to reproduce major observed features of the vertical nutrient and plankton structures through a series of trial simulations and sensitivity studies. Choosing the biological parameter values to be more appropriate for diatoms and mesozooplankton community as listed in Table 1, a model simulation in accord with the classical two bloom structure [Sorokin, 1983; Vinogradov, 1992] is described below. The evolution of the system is given first on the basis of events and processes taking place during the year. Some aspects of the model dynamics and the model versus data comparison are presented next. 


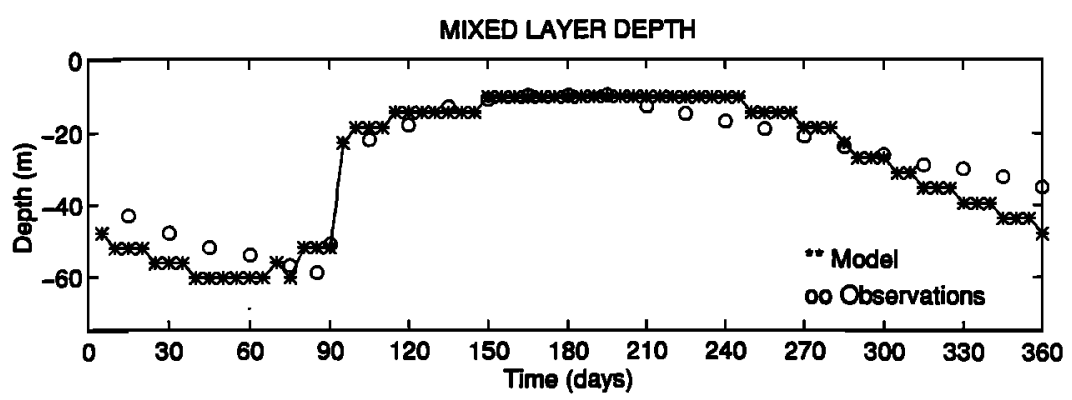

Figure 4a. Comparison of the seasonal cycle of the mixed layer depth estimated from the climatological data with that computed by the model.

4.2.1. Annual distributions and description of events. The temporal and vertical distributions of the phytoplankton (Figure 5a), zooplankton (Figure 5b), detritus (Figure 5c), and nitrate and ammonium (Figures $5 \mathrm{~d}$ and $5 \mathrm{e}$ ) reveal several phases within the year in harmony with the surface layer physical structure. The entire summer and early autumn period is characterized by the nutrient depletion $\left(\mathrm{N} \sim 0.2 \mathrm{mmol} \mathrm{m}^{-3}\right)$ and low phytoplankton biomass $\left(\sim 0.1 \mathrm{mmol} \mathrm{N} \mathrm{m}^{-3}\right)$ within the mixed layer. Phytoplankton biomass is low because, with the decline of $K_{h}$ from its winter values of $>100 \mathrm{~cm}^{2} \mathrm{~s}^{-1}$ to $<10$ $\mathrm{cm}^{2} \mathrm{~s}^{-1}$, the nutrient supply from nutrient rich waters below the mixed layer is no longer possible and all the phytoplankton biomass is consumed by herbivores in the surface waters. The nitrate concentrations at depths immediately below the seasonal thermocline increase rapidly, which, together with the sufficient light availability, allows some subsurface phytoplankton biomass production in the layer between the seasonal thermocline and the base of the euphotic zone during the May-July period. The phytoplankton patches are mostly concentrated immediately below the surface mixed layer between the depths of about $20-30 \mathrm{~m}$ but may extend up to $\sim 50 \mathrm{~m}$.

As the seasonal thermocline weakens and the deepening of the mixed layer begins by the end of October, the surface layer starts to be enriched with nutrients entrained from below. The late autumn phytoplankton bloom is developed later during the second half of November. This is identified with the peak phytoplankton concentrations of about $0.35 \mathrm{mmol} \mathrm{N} \mathrm{m}$ within the upper 30-35 m layer. The bloom terminates within the first half of December after which the entire winter season, until the end of February, is characterized by low concentra- tions ( $\sim 0.10 \mathrm{mmol} \mathrm{N} \mathrm{m}^{-3}$ ) of phytoplankton biomass. The nutrients used up in the euphotic layer during the autumn bloom period are compensated immediately by the continuous supply from the lower levels, as a result of strong vertical mixing generated by the winter convective overturning mechanism. The mixed layer nitrogen concentration increases gradually to maximum values of about $2 \mathrm{mmol} \mathrm{N} \mathrm{m}^{-3}$ at the end of February (Figure 5e) when the water column is overturned completely and a deepest and coolest mixed layer formation is established. The spring bloom initiates within the first week of March. The bloom reaches its maximum intensity of $\sim 1.9$ mmol $\mathrm{N} \mathrm{m}^{-3}$ within the upper $30 \mathrm{~m}$ of the water column a week later. The bloom event continues for about a week to 10 days and then begins to degrade with phytoplankton concentrations of about $0.1-0.2 \mathrm{mmol} \mathrm{N} \mathrm{m}^{-3}$ toward the end of the month; soon after the nitrogen stock is consumed almost completely.

Remineralization of the particulate organic material following degradation of the spring bloom produces ammonium with typical concentrations of about $0.5 \mathrm{mmol} \mathrm{N} \mathrm{m}^{-3}$ during April. A part of the ammonium concentration is used in the regenerated production; the rest is converted to the nitrate form through the nitrification process. The contribution of the latter process to the nitrate formation is evident in Figure 5e by the 20-m-thick band of relatively uniform concentrations from immediately below the thermocline to the depths of about $50 \mathrm{~m}$ during April to November period, when compared with the linearly decreasing initial profile (Figure $2 c$ ). In the model the nitrification is considered as a direct conversion from the ammonium to the nitrate without having the intermediate step of

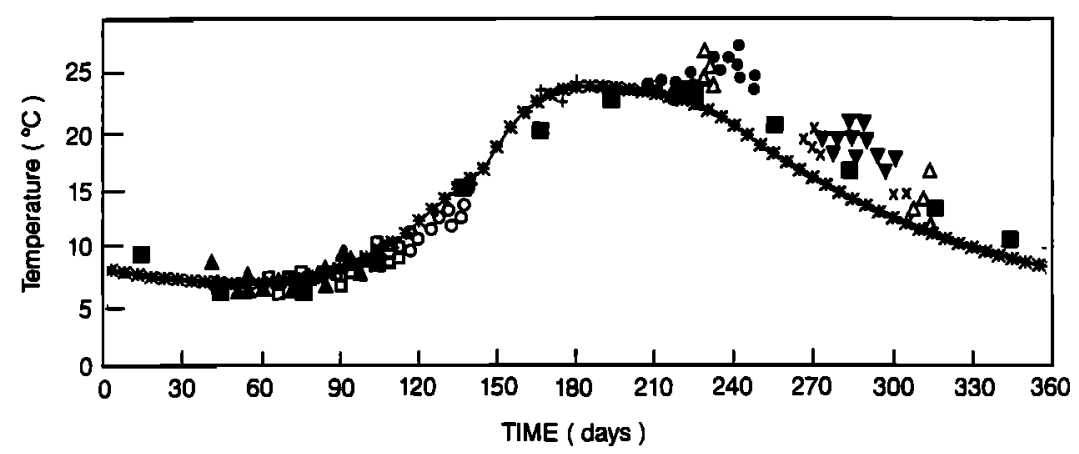

Figure 4b. Comparison of the seasonal cycle of the surface temperature computed by the model with observations from the central Black Sea. The observed surface temperature distribution is redrawn from Vedernikov and Demidov [1993]. The monthly mean climatological surface temperature data are shown by solid squares after Oguz et al., 1992. Stars and continuous line represent the model. Open and solid triangles, solid reverse triangles, open and solid circles, and crosses represent observations. 
(a) DAYS PHYTOPLANKTON CONC. (mmol/m3)

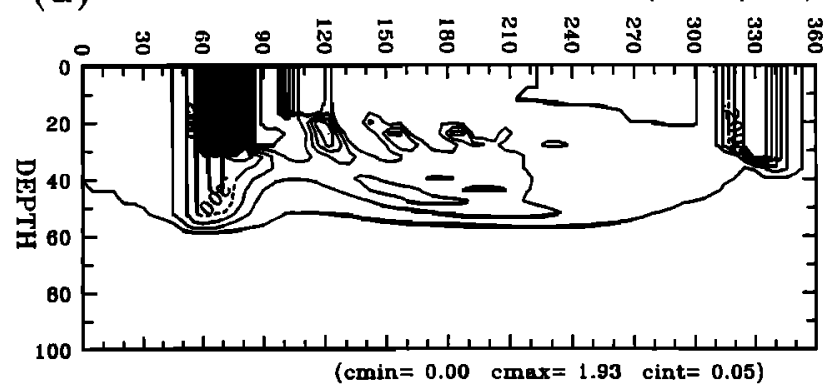

(b) DAYS HERBIVORE CONC. (mmol/m3)

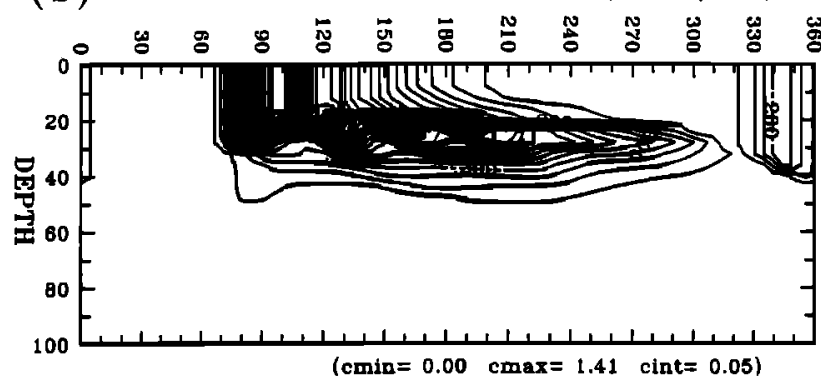

(C) DAYS DETRITUS CONC. $(\mathrm{mmol} / \mathrm{m} 3)$

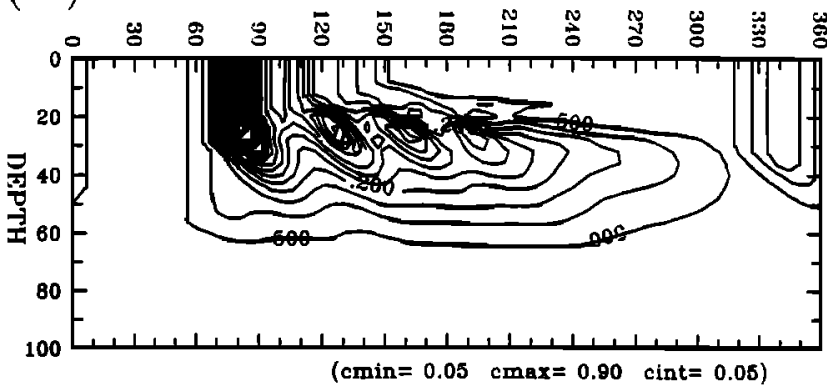

(d) DAYS AMMONIUM CONC. (mmol/m3)

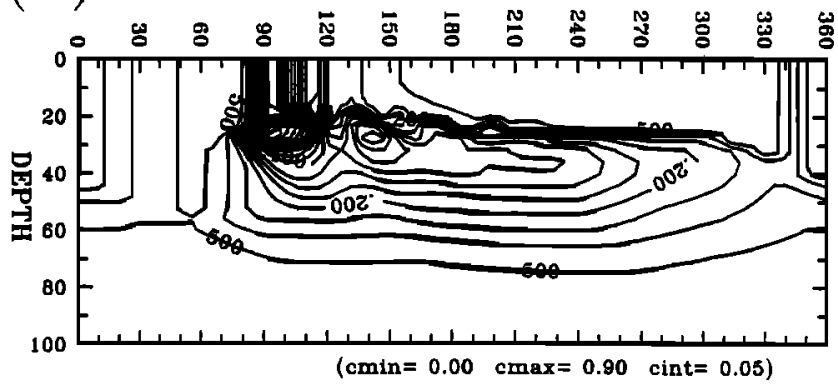

(e) DAYS NITRATE CONC. (mmol $/ \mathrm{m} 3)$

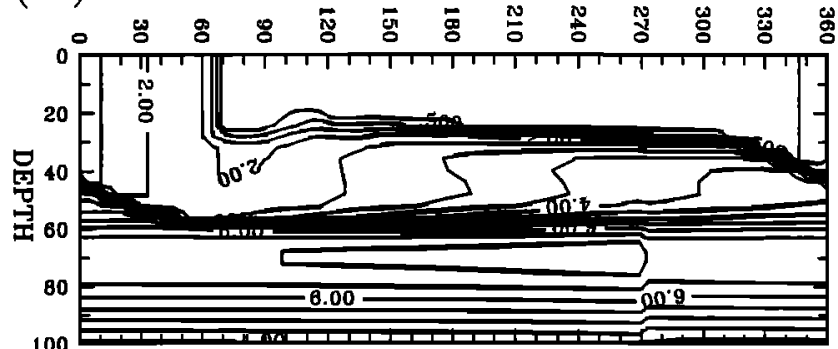

100

$(\mathrm{cmln}=0.50 \operatorname{cmax}=7.30 \mathrm{clnt}=0.50)$

Figure 5. Depth and time variations of the (a) phytoplankton, (b) zooplankton, (c) detritus, (d) ammonium, and (e) nitrate concentrations (micromoles of $N$ per cubic meter) computed by the model. the nitrite formation. In reality, however, a fraction of the total oxidized nitrogen appears in the nitrite form near the base of the euphotic zone [Codispoti et al., 1991]. The nitrate accumulation in the $30-50 \mathrm{~m}$ zone forms eventually the main nutrient source which is later brought up to the surface during the convective overturning process and used during the next spring bloom. A typical nitrate profile in this period is thus characterized by very low values within the surface layer, increasing gradually below the thermocline up to about 50-m depth and then a rapid increase to its subsurface maximum further below. This structure agrees well with the R/V Knorr observations performed during summer 1988 [Codispoti et al., 1991, Figures 9-11]. In the layer below the subsurface maximum the nitrification process leads to a slight increase of nitrate concentrations during the year as compared with the zero concentrations in the initial profile. The present model does not incorporate the denitrification process which normally prevents the nitrate accumulation near the anoxic interface.

The third phytoplankton growth process takes place during the second week of April, about 2-3 weeks after the complete termination of the March bloom. The ammonium, produced as a product of the March bloom and trapped within the recently formed mixed layer about the seasonal thermocline, leads to a short-period (about 1 week) phytoplankton production comparable with the intensity of the late fall bloom episode ( $\mathrm{P}$ $0.30 \mathrm{mmol} \mathrm{N} \mathrm{m}{ }^{-3}$ ). This is surface intensified bloom extending only to the depths of $20 \mathrm{~m}$.

The summer season is the period of low production. The stratification and subsequent formation of the strong seasonal thermocline inhibit nutrient flux into the shallow mixed layer from below. Since the regenerated products have already been utilized in the mixed layer, severe nutrient limitation prohibits development of the bloom during the summer season. However, some phytoplankton production $\left(P \sim 0.20 \mathrm{mmol} \mathrm{N} \mathrm{m}^{-3}\right)$ occurs until July in deeper levels where a favorable balance of light and nutrient availability still exists.

As far as the phytoplankton distribution during the year is concerned, the model reproduces the major observed features depicted earlier in Figures 2a-2d. The thicknesses of uniform phytoplankton layers during the November and March blooms as well as the position of subsurface maximum layer during the summer months agree qualitatively with the observations shown in Figure 2a. Additional remarks on the model and data comparison will be given below in section 4.2.5.

The yearly distributions of zooplankton and detritus follow closely that of the phytoplankton with a time lag of approximately 2 weeks. The maximum zooplankton concentrations of about $0.2,0.4$, and $0.3 \mathrm{mmol} \mathrm{N} \mathrm{m} \mathrm{m}^{-3}$ occur following the late autumn and early spring blooms as well as the period of summer subsurface phytoplankton maximum, respectively.

The detrital material sinking with the fall speed of $1.0 \mathrm{~m}$ day $^{-1}$ reveals a diffusive vertical distribution within the euphotic layer for most of the year. Its concentrations are almost twice the zooplankton's during the summer months following the major spring bloom event. The material is continuously remineralized and converted to the nitrogen form which becomes available for recycling into the upper levels by the late autumn. As we noted above, relative to its initial distribution, the nitrogen is particularly accumulated at depths where the detritus concentration has a maximum.

We emphasize here that the detritus pool acting as a source in the nitrogen-plankton cycling process is assumed to be formed by small particles generated mainly by the zooplankton 
egestion with low sinking velocities of the order of $1 \mathrm{~m}$ day ${ }^{-1}$. The larger particles sinking with much higher fall speeds are assumed not to take any role in the remineralization process of the detrital material. The effect of larger sinking velocity of the particles on the plankton dynamics will be discussed below.

4.2.2. Annual nitrogen budget. One way of checking internal consistency of the model dynamics is to evaluate the balance of terms governing the plankton dynamics, when integrated over the depth of the euphotic zone and over the year. This computation also provides the intercompartmental transfer rates and the fluxes across the base of the euphotic layer, which constitute a crucial part of our understanding of the biogeochemical cycle of the upper layer of the Black Sea. Though not impossible, this is extremely difficult to achieve by measurements.

Defining the total particulate organic nitrogen content PON as the sum of phytoplankton, herbivore, and detritus concentrations and the total nitrogen content NA as the sum of nitrate and ammonium concentrations,

$$
\mathrm{PON}=P+H+D \quad \mathrm{NA}=N+A
$$

(7)-(12) can be reduced to the following forms when integrated over the euphotic zone and over the year, together with using the zero-flux conditions at the sea surface.

$$
\begin{aligned}
\iint \Phi(I, N, A) P d z d t= & \iint(\mu H+\varepsilon D) d z d t \\
& -\int\left(\Gamma_{\mathrm{PON}}+w_{s} D\right)_{h} d t \\
\iint \Phi(I, N, A) P d z d t= & \iint(\mu H+\varepsilon D) d z d t \\
& +\int\left(\Gamma_{\mathrm{NA}}\right)_{h} d t
\end{aligned}
$$

where $\Gamma_{\text {PON }}$ and $\Gamma_{\text {NA }}$ are the vertical diffusive fluxes of PON and NA, respectively, and the subscript $h$ refers to the base of the euphotic layer.

The annual budget (Figure 6) given by (23) and (24) implies an approximate balance between the external input of total nitrogen flux into the euphotic layer from below $\left(\Gamma_{\mathrm{NA}}=41.5\right.$ $\mathrm{mmol} \mathrm{m} \mathrm{m}^{-2} \mathrm{yr}^{-1}$ ) and the sum of the total particulate organic matter flux $\left(\Gamma_{\text {PON }}=5.7 \mathrm{mmol} \mathrm{m} \mathrm{mr}^{-2} \mathrm{yr}^{-1}\right)$ and the detrital sinking flux $\left(w_{s} D=35.3 \mathrm{mmol} \mathrm{m}{ }^{-2} \mathrm{yr}^{-1}\right)$ from the base of the euphotic zone. They further indicate that the total production $\left(\Phi P=532 \mathrm{mmol} \mathrm{m}^{-2} \mathrm{yr}^{-1}\right)$ is compensated by the ammonium generated within the euphotic zone through the remineralization of detritus $\left(\varepsilon D=304.2 \mathrm{mmol} \mathrm{m}^{-2} \mathrm{yr}^{-1}\right)$ and zooplankton excretion $\left(\mu H=196.7 \mathrm{mmol} \mathrm{m}^{-2} \mathrm{yr}^{-1}\right.$ ) plus the external input of total nitrogen flux into the euphotic zone from below $\left(\Gamma_{\mathrm{NA}}=41.5 \mathrm{mmol} \mathrm{m}^{-2} \mathrm{yr}^{-1}\right)$. The nitrate and ammonium uptakes are $193.5 \mathrm{mmol} \mathrm{m}^{-2} \mathrm{yr}^{-1}$ and 338.5 mmol m $\mathrm{m}^{-2} \mathrm{yr}^{-1}$, respectively, which account for 36 and $64 \%$ of the annual gross primary production. However, because a large part of the nitrate uptake is derived from the ammonium oxidation, all of the nitrate uptake cannot be accounted for the new generation. It is therefore more appropriate to define the $f$ ratio as the ratio of nitrate flux across the base of the euphotic layer to the total primary production. The annual mean value
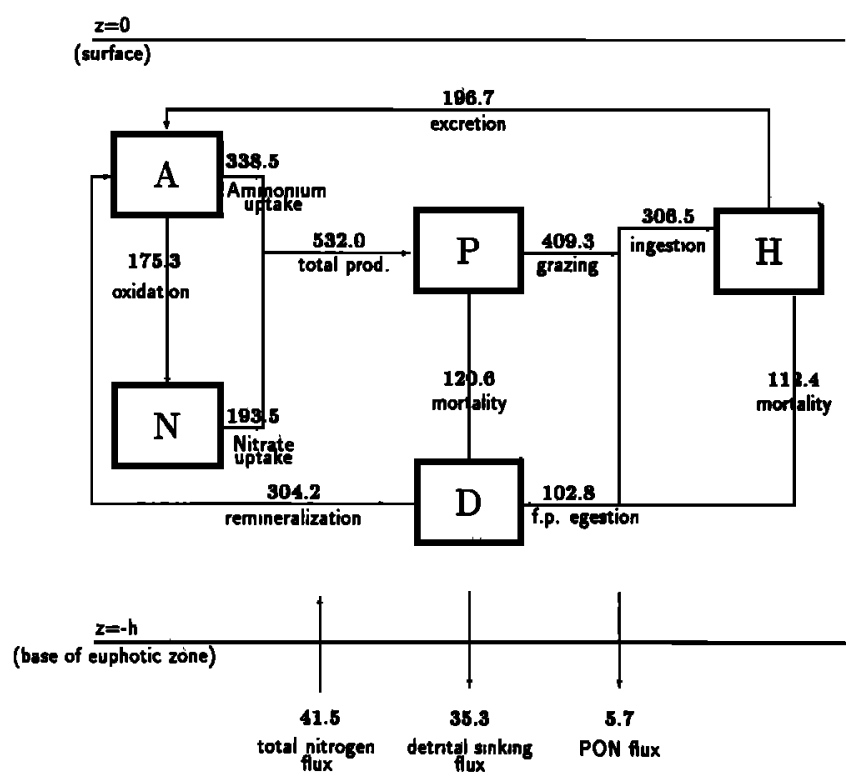

Figure 6. The annual nitrogen budget (micromoles of $\mathrm{N}$ per square meter per year) in the euphotic zone. PON is particulate organic nitrogen.

of this ratio is $41.5 / 532=0.08$. Furthermore, $58 \%$ of the primary production was assimilated by zooplankton and $20 \%$ is lost to detritus as fecal pellet egestion. The detritus remineralization of $304.2 \mathrm{mmol} \mathrm{m}^{-2} \mathrm{yr}^{-1}$ accounts for almost all the annual ammonium production, whereas the contribution of the zooplankton excretion ( $196.7 \mathrm{mmol} \mathrm{m}^{-2} \mathrm{yr}^{-1}$ ) is comparable with the ammonium oxidation flux of $175.3 \mathrm{mmol} \mathrm{m}^{-2} \mathrm{yr}^{-1}$. Finally, we note that the yearly mean detrital sinking flux estimate of $35.3 \mathrm{mmol} \mathrm{N} \mathrm{m}^{-2} \mathrm{yr}^{-1}$ at the base of the euphotic layer compares well with the observed value of $11.5 \mathrm{mmol} \mathrm{N}$ $\mathrm{m}^{-2} \mathrm{yr}^{-1}$ obtained from the sediment trap measurements during May 1988 [Karl and Knauer, 1991].

4.2.3. Dynamics of the phytoplankton blooms. The main mechanisms controlling the initiation, development, and degradation of the March and November blooms, as well as the subsurface maxima of the summer season, are described briefly in this section. We first consider the relative roles of light and nutrient uptake in the primary production process. The control of the phytoplankton growth by either light or nutrient limitation during the year is highlighted in Figures $7 \mathrm{a}$ and $7 \mathrm{~b}$. The most striking feature of the nutrient limitation function $\beta_{t}(N$, A) (Figure $7 \mathrm{~b}$ ) is the presence of very sharp, narrow high gradient zone. This is situated approximately at $30-40 \mathrm{~m}$ depths for most of the year, except during the January and February period, and separates the low $\beta_{t}$ region near the surface from the region of its high values (close to one) immediately below. The light limitation function $\alpha(I)$, on the other hand, has the opposite structure with decreasing values toward the deeper levels (Figure 7a). The net growth function (Figure 7c), computed by choosing the minimum of these two, is thus governed by the nitrogen limitation near the surface and by the light limitation at deeper levels. A subsurface maxima region is present in between, at the depths of about $30-40 \mathrm{~m}$ where they both have the moderate values. During the summer season this is responsible for the subsurface phytoplankton production (compare Figure 5a).

We note from Figure 7c that highest values of the net growth 
(a) DAYS

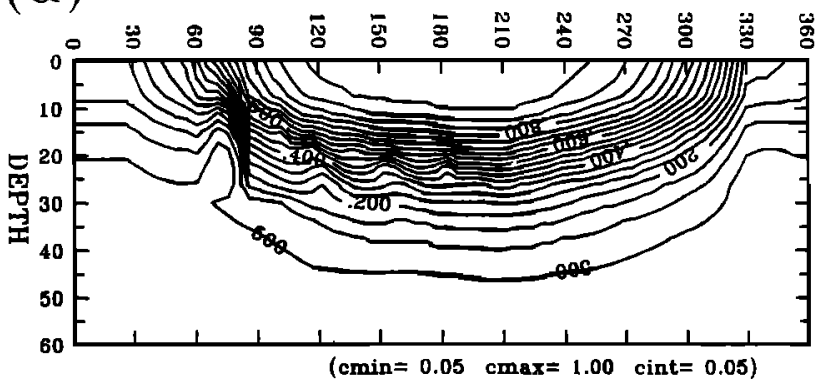

(b) DAYS

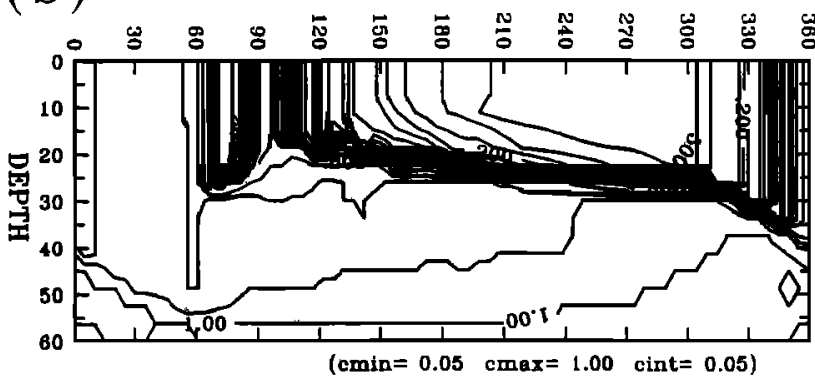

(C) DAYS

NET LIMITATION FUNC.

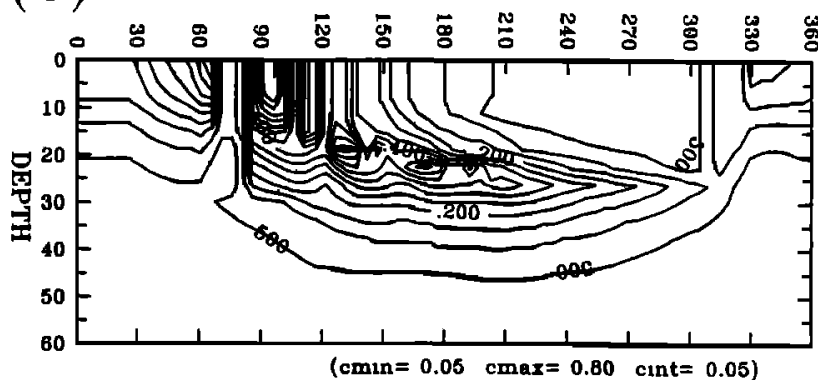

Figure 7. The depth and time variations of the (a) nondimensional light limitation function, (b) nondimensional nutrient limitation function, and (c) the net limitation function within the year.

function within the upper $25 \mathrm{~m}$ layer occur during the January and February months. But the bloom development takes place at a later time, during early March. The absence of bloom generation in the midwinter period has two dynamical reasons. First, although the net growth function has the exceptionally high values, the amount of phytoplankton biomass in the water column is not sufficient to keep the primary production (i.e., the first term on the right-hand side of (8)) above a certain level sufficient to initiate the bloom. Second, the surface layer has relatively strong downward diffusion, which counteracts against primary production and therefore prevents the bloom development. However, as soon as the intensity of the vertical mixing diminishes at the end of February (Figure 8a), a new balance is established between the primary production (Figure 9a) and the time change of the phytoplankton biomass (Figure 9d) with almost no contributions from the grazing and the mortality terms. This new balance leads to an exponential growth of the phytoplankton concentration in the mixed layer. Soon after the initiation phase, the zooplankton grazing (Figure $\bar{y}$ ) starts dominating the system and balances the primary
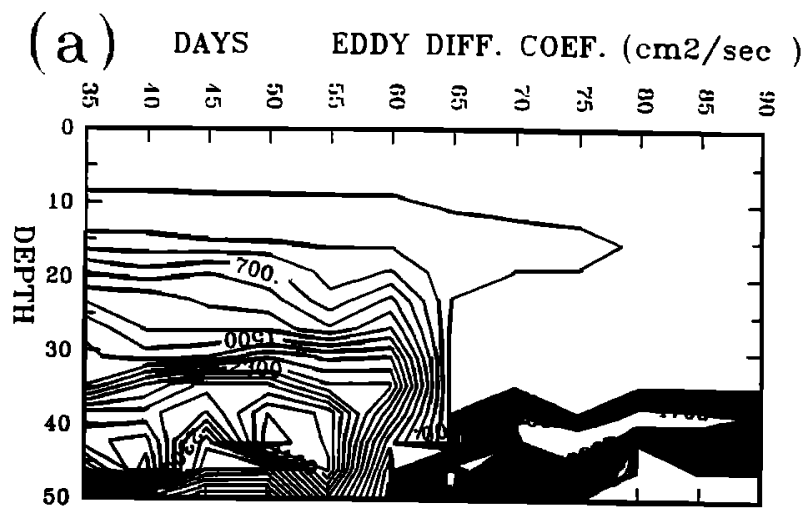

$($ cmin $=100 . \quad$ cmax $=5000$. cint $=200$. $)$

(b) DAYS TEMPERATURE (c)

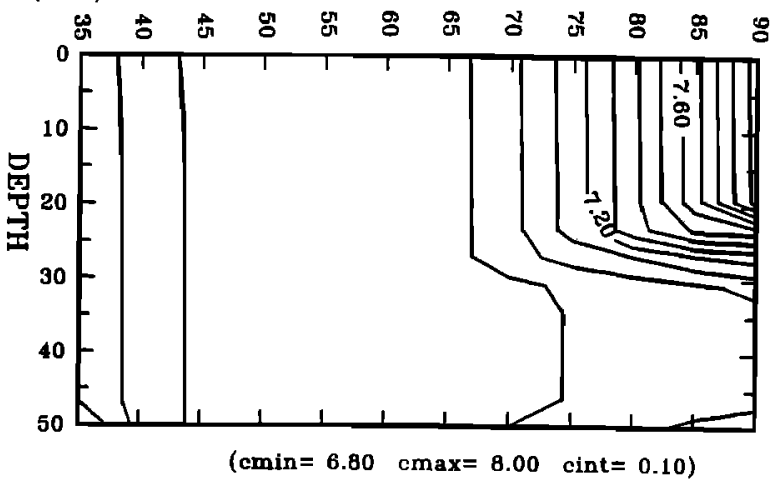

(c) DAYS PHYTOPLANKTON CONC (mmol/m3)

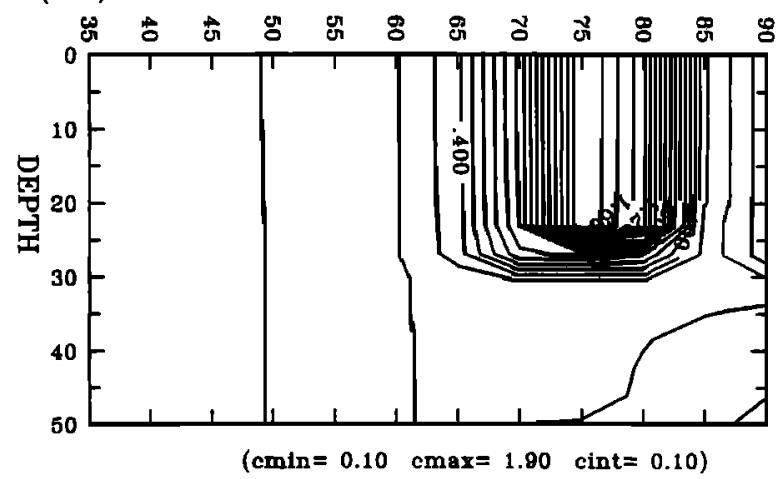

Figure 8. The depth and time variations of the (a) eddy diffusion coefficient (square centimeters per second), (b) temperature (degrees Celsius), and (c) phytoplankton concentration (micromoles of $\mathrm{N}$ per cubic meter) during the FebruaryMarch period.

production. This continues until the nitrate stocks in the mixed layer are depleted and the nitrate-based primary production weakens. At the same time, rapid recycling of the particulate material allows for the ammonium-based production. also contributing to the bloom development (Figure 9b). The bloom terminates abruptly toward the end of March when the ammonium stocks are also no longer available for the regenerated production.

The downward diffusion process mentioned above is evident in the February profile of Figure 8a by gradual increase of $K_{h}$ values toward the middepth of the mixed layer. The termination of the convective mixing process at day 65 is implied in 
(a) DAYS NEW PRODUCTION $\mathrm{mmol}(/ \mathrm{m} 3$ day $)$

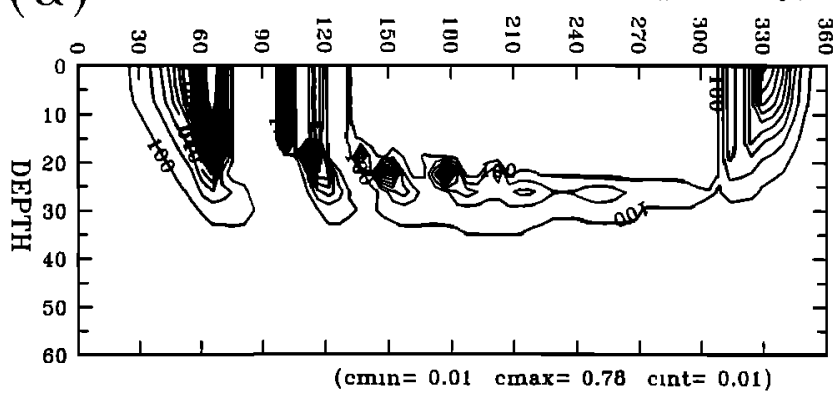

(b) DAYS REG. PRODUCTION mmol/(m3 day)

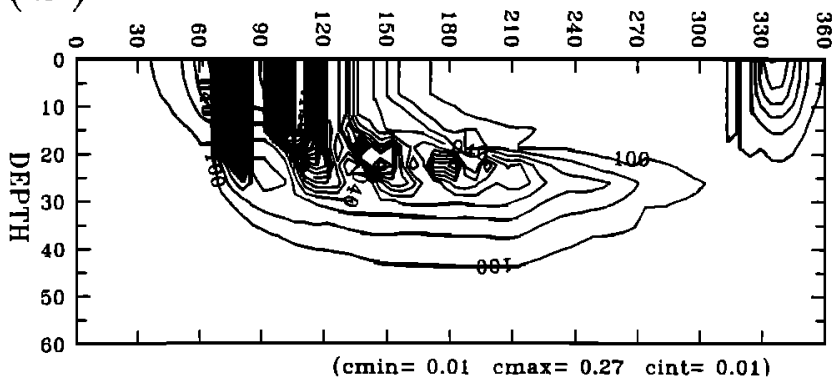

(C) DAYS ZOO. GRAZING $\mathrm{mmol} /(\mathrm{m} 3$ day)

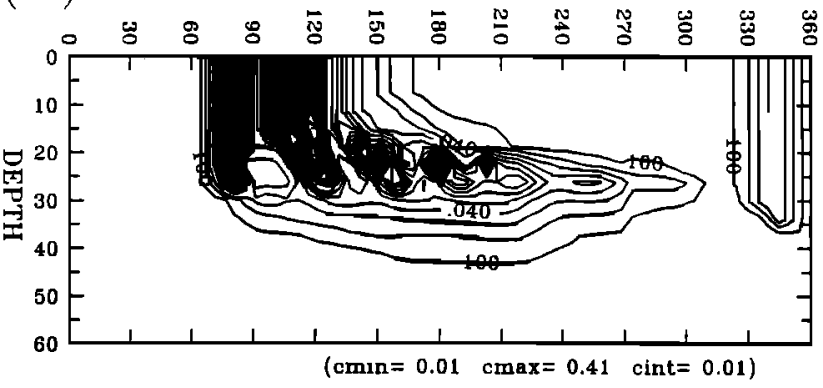

(d) DAYS TIME CHANGE $\mathrm{mmol} /(\mathrm{m} 3$ day)

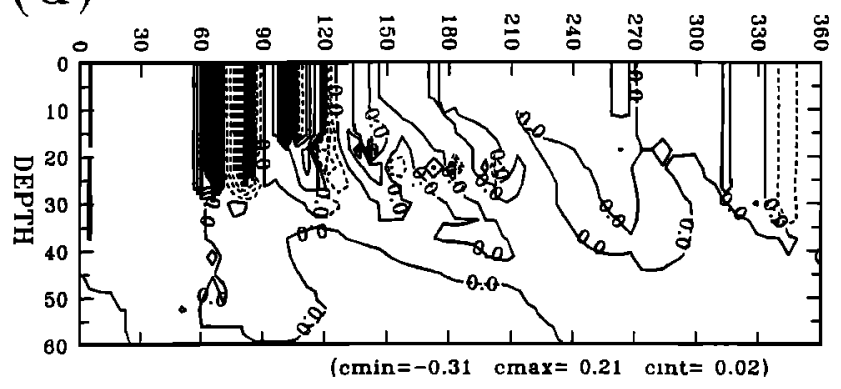

Figure 9. The depth and time variations of the (a) new production, (b) regenerated production, (c) zooplankton grazing, and (d) time change of phytoplankton (micromoles of $\mathrm{N}$ per cubic meter per day).

Figure 8a by sudden reduction of $K_{h}$ values from the order of 1000 to of the order of $10 \mathrm{~cm}^{2} \mathrm{~s}^{-2}$. Shown further in Figures $8 \mathrm{~b}$ and $8 \mathrm{c}$ is that the period of high $K_{h}$ values is identified with the vertically uniform temperature structure of about $6.8^{\circ} \mathrm{C}$ and the phytoplankton structure of approximately $0.1 \mathrm{mmol} \mathrm{N}$ $\mathrm{m}^{-3}$. Following the termination of convective overturning, the detrainment process, which is indicated by the zone of high $K_{h}$ values at $40-50 \mathrm{~m}$ depths after day 65 (see mid-March $K_{h}$ profile in Figure $3 c$ ), begins establishing the subsurface strat- ification. As the mixed layer temperature increases by about $0.3^{\circ} \mathrm{C}$ (from 6.9 to $7.2^{\circ} \mathrm{C}$ ), the bloom attains its peak amplitude within the next 10 days (Figure $8 \mathrm{c}$ ).

The similar process of bloom generation repeats during November. Again, a week balance between the nitrate-based production and the time rate of change of phytoplankton concentration initiates the exponential phytoplankton growth, which in turn strengthens the new production. The bloom terminates as soon as the nitrate stocks are depleted in the euphotic zone. The ammonium-based regenerated production plays little role in the autumn bloom. It, however, contributes more to the subsurface phytoplankton development during the summer months (Figures 9a and 9b).

4.2.4. Annual variability in the bloom structures: Sensitivity to parameter setting. During the implementation phase of the model to the Black Sea conditions a considerable number of sensitivity experiments have been carried out to understand the model response under different sets of conditions. We present a few examples to give an idea of how the setting of the biological parameters is important to obtain the annual cycle consistent with the observations in the Black Sea. One such parameter is the light efficiency parameter $a$. It is hard to determine its value from the observations. An increase in its standard value of $0.01-0.03 \mathrm{~m}^{2} \mathrm{~W}^{-1}$ shifts the autumn bloom to the winter covering the period from the beginning of January to the end of February. No spring bloom follows this midwinter blooming, and the peak concentrations of about 0.6 mmol $\mathrm{N} \mathrm{m}^{-3}$ are much lower than those of the spring bloom but comparable to those of the autumn bloom of the standard run. This structure is modified slightly when the assimilation capacity of the zooplankton grazing, $\gamma$, is also reduced to 0.5 , in addition to the setting of $a=0.03$. In this case the bloom continues until the end of March with its maximum development taking place between the last week of February and mid-March (Figure 10a). The position of the summer subsurface maxima is also shifted below by about $10 \mathrm{~m}$.

Altering the value of $y$ from 0.75 to 0.50 shifts the autumn bloom toward the winter (Figure 10b). Lowering its value implies effectively changing the preference in the biological system from zooplankton to the detritus. This is noted by the considerable increase on the detritus concentration (maximum values are now 1.67 as compared with $0.92 \mathrm{mmol} \mathrm{N} \mathrm{m}^{-3}$ of the standard run) and consequently the more than $1 \mathrm{mmol} \mathrm{N} \mathrm{m}^{-3}$ increase in the ammonium and nitrate concentrations. This is eventually reflected as a longer and stronger late autumn bloom formation during the December-January period with the peak concentrations of about $0.6 \mathrm{mmol} \mathrm{N} \mathrm{m}^{-3}$. The spring bloom again initiates at the beginning of March, but it is now much stronger (maximum value $2.4 \mathrm{mmol} \mathrm{N} \mathrm{m}^{-3}$ ) and continues almost the whole month. The subsurface production is also increased almost twice during the April-June period and extends to deeper levels. This has a better resemblence with the observed subsurface chlorophyll-a structure given in Figure 2a.

The sinking rate of the particulate organic matter, $w_{s}$, is one of the most critical parameters in the model. The value of $w_{s}$ appropriate for the model simulations is $1.0 \mathrm{~m} \mathrm{day}^{-1}$, which implies that the main contribution to the detritus pool comes from small particles with lower sinking velocity generated mainly by the zooplankton egestion. The fast sinking, larger particles do not contribute to the processes taking place within the euphotic zone. The choice of greater values causes faster sinking of the detrital material toward the deeper levels, thereby decreasing the detritus and subsequently the nitrogen 
concentrations in the euphotic layer. The sinking material thus effectively becomes lost from the euphotic zone. Figure 10c shows the result of the standard run when the sinking velocity is taken as $3.0 \mathrm{~m} \mathrm{day}^{-1}$ within the upper $50 \mathrm{~m}$, decreasing linearly to $0.5 \mathrm{~m} \mathrm{day}^{-1}$ at $100 \mathrm{~m}$ and staying at this value below this depth. This minor change in the value of $w_{s}$ alters the whole biological system drastically. There now exists only a weak March bloom, with almost no zooplankton biomass and detritus in the water column. The euphotic layer is depleted in both ammonia and nitrate, which are, however, accumulated at deeper levels. As suggested by Totterdell et al. [1993], a timedependent vertical sinking velocity parameterization seems to be a better choice with higher rates at the end of the spring bloom of larger diatom cells and lower rates within the rest of the year dominated by fragments of smaller cells and fecal pellets.

4.2.5. Model-data comparison. For the model versus data intercomparison we present the annual distributions of the chlorophyll-a and the total primary productivity shown by the continuous lines in Figures $2 b$ and $2 c$. The euphotic layer averaged chlorophyll-a concentrations (Figure 2a) are computed from the phytoplankton biomass values using the conversion factor of $1 \mathrm{mg} \mathrm{Chl} \mathrm{m}{ }^{-3}$ being roughly equivalent to 1 mmol $\mathrm{N} \mathrm{m}^{-3}$. This conversion assumes a general algal carbon to chlorophyll-a ratio of $\sim 100$ and carbon to nitrogen ratio of $\sim 8.5$ [Karl and Knauer, 1991] for a nitrogen limited system. Comparison of computed chlorophyll concentrations with those given by the observations indicates that the peak concentration of about $1.5 \mathrm{mg} \mathrm{Chl} \mathrm{m} \mathrm{m}^{-3}$ agrees fairly well with the data. The model's typical postbloom and summer $\mathrm{Chl}$ values are about $0.2 \mathrm{mg} \mathrm{Chl} \mathrm{m}^{-3}$, whereas the data attain the values of $0.3-0.4 \mathrm{mg} \mathrm{Chl} \mathrm{m}{ }^{-3}$ during the same period. The Chl concentration during the autumn bloom is predicted as $0.4 \mathrm{mg} \mathrm{Chl}$ $\mathrm{m}^{-3}$. The data, however, tend to suggest relatively higher values varying in the range of $0.4-1.0 \mathrm{mg} \mathrm{Chl} \mathrm{m}^{-3}$.

The euphotic layer integrated primary production computed by the model yields a better agreement with the composite data (Figure $2 \mathrm{c}$ ). The integrated primary productivity attains its maximum value of $9.0 \mathrm{mmol} \mathrm{N} \mathrm{m}{ }^{-2}$ day $^{-1}\left(\sim 900 \mathrm{mg} \mathrm{C} \mathrm{m}^{-2}\right.$ day $^{-1}$ ) during the period of the March bloom. This compares favorably well with the measured bloom productivity of $400-$ $1300 \mathrm{mg} \mathrm{C} \mathrm{m}^{-2}$ day $^{-1}$. The spring bloom is followed by the three smaller peaks of $\sim 500-600 \mathrm{mg} \mathrm{C} \mathrm{m}^{-2}$ day $^{-1}$ associated with the regenerated primary production in the spring period (see Figure $9 \mathrm{~b}$ ). The primary production estimates of $\sim 300-$ $500 \mathrm{mg} \mathrm{C} \mathrm{m}^{-2}$ day $^{-1}$ during May are also comparable with the May 1988 measurements of 339 and $573 \mathrm{mg} \mathrm{C} \mathrm{m}^{-2}$ day $^{-1}$ at two stations within the central Black Sea [Karl and Knauer, 1991]. Somewhat weaker subsurface production is traced in the model until July. August to October is shown to be the least productive period characterized by the values of less than 200 $\mathrm{mg} \mathrm{C} \mathrm{m}{ }^{-2}$ day $^{-1}$, whereas the data values vary from 200 to 500 $\mathrm{mg} \mathrm{C} \mathrm{m}{ }^{-2}$ day $^{-1}$ in the same period. The main reason for the weaker productivity in the model during the summer and early autumn seasons is the weak nutrient supply from the lower levels due to insufficient vertical mixing. In the threedimensional models, on the other hand, it is reasonable to expect stronger productivity in the surface layer as a result of lateral nutrient supply associated with the horizontal advective transport.

The model seems to predict the observed chlorophyll and primary production values reasonably well for most parts of the year except during the autumn bloom season. The model es- (a) DAYS PHYTOPLANKTON CONC. (mmol $/ \mathrm{m3}$ )

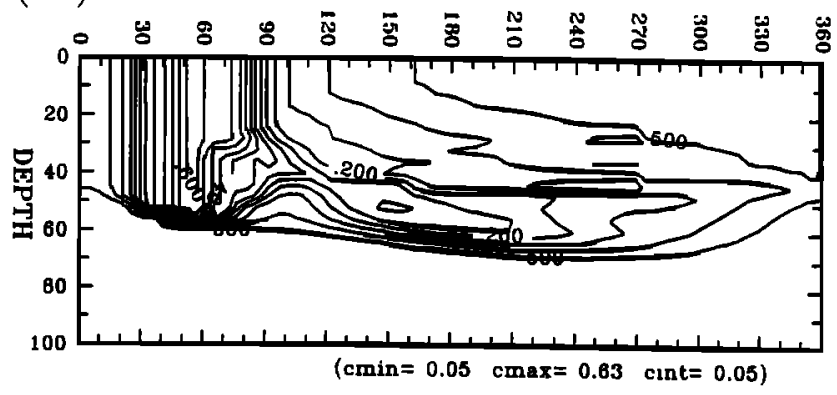

(b) DAYS PHYTOPLANKTON CONC. (mmol/m3)

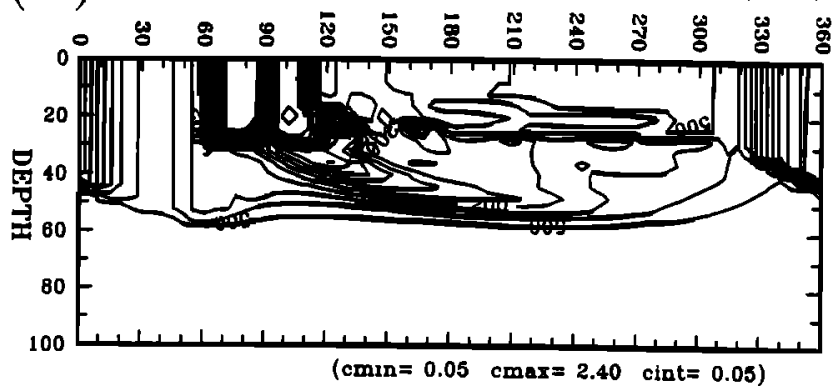

(C) DAYS PHYTOPLANKTON CONC. (mmol $/ \mathrm{m} 3$ )

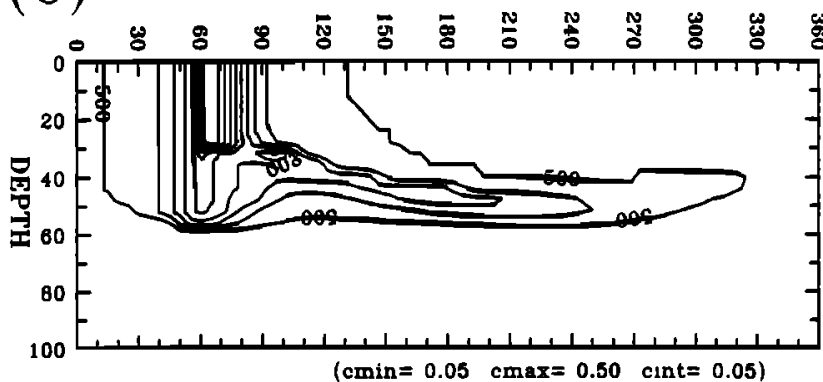

Figure 10. Depth and time variations of the phytoplankton concentration when the parameters of the reference experiment are varied to (a) $a=0.03$ and $\gamma=0.5$, (b) $\gamma=0.5$, and (c) variable $w_{s}$ with a value of $3.0 \mathrm{~m}^{-1 a y^{-1}}$ within the upper 50 $\mathrm{m}$, decreasing linearly to $0.5 \mathrm{~m} \mathrm{day}^{-1}$ at $100 \mathrm{~m}$ and staying at this value for the rest of the water column.

timate of autumn primary productivity peak of $200 \mathrm{mg} \mathrm{C} \mathrm{m}^{-2}$ day $^{-1}$ is somewhat lower than the observations. Considering the fact that only the convective overturning process (which is also not very effective during the late autumn) is responsible for the nitrate supply from the subsurface levels, this is not surprising. The model does not take into account other vertical mixing mechanisms as well as possible contributions from the lateral nitrate fluxes. The autumn season is known to be characterized by weekly storms which are expected to enhance temporarily upward flux of nitrate into the mixed layer (see Klein and Coste [1984] for the efficiency of this process and Radach and Moll [1993] for the North Sea example). Furthermore, the photosynthetic bacterial production which is not incorporated in the model may account for a part of the production in the autumn period. Although their observations are not performed in the same season, Karl and Knauer [1991] indicated that the bacterial production constitutes almost half of the photoautotrophic production. This process may also 
contribute to the subsurface phytoplankton generation during the summer.

\section{Summary and Conclusions}

A deterministic time-dependent, one-dimensional, physicalbiological coupled upper layer model is used to study the annual cycle of plankton dynamics under seasonal physical variability in the central Black Sea. The biological model considers only the lower trophic level food web represented by the phytoplankton and zooplankton biomasses, detritus, and nitrogen (nitrate and ammonium). It therefore provides one of the simplest possible representation of conditions and processes which may describe the plankton-nutrient dynamics in the central Black Sea.

It is found that initiation of the spring bloom depends crucially on the local mixing conditions and follows the weakening of the convective overturning mechanism. As soon as the surface layer of the water column gains a slight stability, the bloom commences before the formation of the seasonal thermocline. This suggests the timing of the bloom is governed by the year-to-year and/or local variabilities in the physical processes, in addition to the biological processes. The spring bloom may thus take place at an earlier period, say in February, during mild winters as pointed out by observations [Vinogradov, 1992].

Following the spring bloom, the model predicts a weaker and shorter phytoplankton growth event within April as the water column begins to stratify and the seasonal thermocline begins to form in the near-surface levels. The formation of this bloom is caused by the ammonium, generated as a by-product of the spring bloom, and trapped in the mixed layer.

A period of very low primary productivity prevails throughout the summer as a consequence of severe nitrogen limitation in the surface mixed layer. However, some phytoplankton production goes on beneath the seasonal thermocline as long as this zone has sufficient light to support the phytoplankton growth. As first demonstrated by Kiefer and Kremer [1981], the presence of "subsurface chlorophyll maxima" is again a consequence of a strong link between the vertically resolved plankton and surface layer dynamics. Toward the end of autumn, rapid destratification of the water column and subsequent intensification of the vertical mixing enhance the nutrient flux to the surface waters and cause a phytoplankton bloom development of 2-3 weeks during the October-December period, depending on the local conditions. The two-bloom structure resembles those seen in the North Sea [Radach and Moll, 1993] and the Baltic Sea [Savchuk and Wulff, 1993].

The numerical experiments implicate the presence of a delicate balance between the growth and grazing processes in the phytoplankton dynamics. In order to get a phytoplankton distribution with two distinct blooms during the late autumn and the early spring, the grazing rate should be a certain fraction of the growth rate. If the grazing pressure is exerted too early and too strong, there will not be sufficient time for the development of sufficiently strong phytoplankton blooms. On the contrary, if it is too weak to be able to control the phytoplankton growth, one long-term blooming event will occur during the December-March period. Once the late autumn bloom is initiated, it will continue for the whole winter season since sufficient nutrient is always entrained into the surface layer during this period. Hence the autumn bloom is not a robust feature of the model, contrary to the March bloom and summer subsurface chlorophyll-a maximum layer. Such modifications on the stan- dard case of the two-bloom phytoplankton structure may also be traced in the data as a part of the year-to-year variabilities of the biological system.

Although this is a rather simplistic model with somewhat crude parameterization of some processes, the simulations show that the model is capable of producing basic features of the plankton-nutrient fields in the Black Sea and helps understanding and interpreting the available observations. In its present form the model describes the general ecosystem characteristics of the sea prior to its deterioration as a result of intense eutrophication and massive growth of the Mnemiopsis leidii. Simulation of the present-day ecosystem characteristics, however, requires improvement of the model in several directions. Some of these are introduction of Mnemiopsis leidii as a separate zooplankton group, introduction of the high-frequency variability and thus incorporation of strong wind-induced mixing, parameterization of intermittent lateral nutrient input into the surface layer, incorporation of the benthic-pelagic interactions for the shelf ecosystem, and reproduction of the occasional summer blooms [Sur et al., 1994] predominated by dinoflagellates and coccoliths (Emiliana huxleyi).

A full validation of the model awaits new observations carried out over a full annual cycle. The forthcoming availability of such new time series measurements will give an opportunity to run the model in its real-time simulation mode. This will improve the model's performance by the addition of new compartments, features, and/or processes, if necessary, for more realistic representation of the ecosystem structure. Such observational efforts are underway in the framework of an international, multiinstitutional scientific research program implemented recently for improving the health of the Black Sea.

Acknowledgments. This work is carried out within the scope of the TU-Black Sea Project sponsored by the NATO Science for Stability Program. It is supported partially by the Turkish Scientific and Technical Research Council (TUBITAK). A part of the work was performed at Massachusetts Institute of Technology (MIT) when the first author was a visiting scientist to MIT, supported by the National Science Foundation grant INT.9310226. The work was completed with the support of the Office of Naval Research, grant N000 14-95-1-0226. Under this grant, T. Oguz was a visiting scientist at MIT during JuneAugust 1995. We thank A. Gaines and M. Follows for their valuable comments.

\section{References}

Altman, E. N., I. F. Gertman, and Z. A. Golubeva, Climatological fields of temperature and salinity in the Black Sea (in Russian), Rep. 115, 111 pp., Sevastopol Branch, State Oceanogr. Inst., Sevastopol, Ukraine, 1987.

Basturk, O., C. Saydam, I. Salihoglu, L. V. Eremeeva, S. K. Konovalov, A. Stoyanov, A. Dimitrov, A. Cociasu, L. Dorogan, and M. Altabet, Vertical variations in the principle chemical properties of the Black Sea in the autumn of 1991, J. Mar. Chem., 45, 149-165, 1994.

Belyaev, V. I., and N. V. Kundufarova, Modeling of the shelf ecosystem, Ecol. Model., 60, 95-118, 1992.

Blumberg, A. F., and G. L. Mellor, A description of a three dimensional coastal ocean circulation model, in Three-Dimensional Coastal Ocean Models, Coastal Estuarine Stud., vol. 4, edited by N. Heaps, pp. 1-16, AGU, Washington, D. C., 1987.

Codispoti, L. A., G. E. Friederich, J. M. Murray, and C. M. Sakamoto, Chemical variability in the Black Sea: Implications of continuous vertical profiles that penetrated the oxic/anoxic interface, Deep Sea Res., Part A, 38, suppl. 2a, S691-S710, 1991.

de Baar, H. J. W., von Liebig's Law of the minimum and plant ecology, Prog. Oceanogr., 33, 347-386, 1994.

Doney, S. C., D. M. Glover, and R. G. Najjar, A coupled, one- 
dimensional biological-physical model for the JGOFS Bermuda Atlantic Time Series Site, Deep Sea Res., Part I, in press, 1996.

Efimov, V. V., and N. A. Timofeev, Investigation of the Black Sea and Azov Sea heat balance, technical report, 237 pp., Ukr. Acad. of Sci., Sevastopol, 1990.

Fasham, M. J. R., H. W. Ducklow, and S. M. McKelvie, A nitrogenbased model of plankton dynamics in the oceanic mixed layer, $J$. Mar. Res., 48, 591-639, 1990.

Fasham, M. J. R., J. L. Sarmiento, R. D. Slater, H. W. Ducklow, and $R$. Williams, Ecosystem behavior at Bermuda station " $S$ " and ocean weather station "India": A general circulation model and observational analysis, Global Biogeochem. Cycles, 7, 379-415, 1993.

Finenko, Z. Z., and D. K. Krupatkina, Primary production in the Black Sea during the winter-spring period, Oceanology, Engl. Transl., 33, 82-88, 1993.

Jassby, A. D., and T. Platt, Mathematical formulation of the relationship between photosynthesis and light for phytoplankton, Limnol. Oceanogr., 21, 540-547, 1976.

Karl, D. M., and G. A. Knauer, Microbial production and particle flux in the upper $350 \mathrm{~m}$ of the Black Sea, Deep Sea Res., Part $A, 38$, suppl. 2, S655-S661, 1991.

Kideys, A. E., Recent dramatic changes in the Black Sea ecosystem: The reason for the sharp decline in Turkish anchovy fisheries, J. Mar. Syst., 5, 171-181, 1994.

Kiefer, D. A., and J. N. Kremer, Origins of vertical patterns of phytoplankton and nutrients in the temperate open-ocean: A stratigraphic hypothesis, Deep Sea Res., Part A, 28, 1087-1105, 1981.

Klein, P., and B. Coste, Effects of wind-stress variability on nutrient transport into the mixed layer, Deep Sea Res., Part A, 31, 21-37, 1984.

Krivenko, O. V., and A. L. Lukjanova, Inorganic nitrogen uptake by Black Sea microplankton in connection with hydrochemical conditions, Oceanology, Engl. Transl., 34, 206-213, 1994.

Lebedeva, L. P., and E. A. Shushkina, The model investigation of the Black Sea community changes caused by Mnemiopsis, Oceanology, Engl. Transl., 34, 79-87, 1994.

Mee, L. D., The Black Sea in crisis: The need for concerted international action, Ambio, 21, 278-286, 1992.

Mellor, G. L., User's Guide for a Three Dimensional, Primitive Equation Numerical Ocean Model, Prog. in Atmos. and Ocean Sci., 35 pp., Princeton Univ., Princeton, N. J., 1990.

Mellor, G. L., and T. Yamada, Development of a turbulence closure model for geophysical fluid problems, Rev. Geophys., 20, 851-875, 1982.

Oguz, T., P. E. La Violette, and U. Unluata, The Black Sea circulation: Its variability as inferred from hydrographic and satellite observations, J. Geophys. Res., 97, 12,569-12,584, 1992.

Oguz, T., et al., Mesoscale circulation and thermohaline structure of the Black Sea observed during HydroBlack'91, Deep Sea Res., Part I, 41, 603-628, 1994

Ovchinnikov, I. M., and Y. I. Popov, Evolution of the cold intermediate layer in the Black Sea, Oceanology, Engl. Transl., 27, 555-560, 1987.

Radach, G., and A. Moll, Estimation of the variability of production by simulating annual cycles of phytoplankton in the central North Sea, Prog. Oceanogr., 31, 339-419, 1993.

Sapozhnikov, V. V., Biohydrochemical barrier along the border of shelf waters of the Black Sea, Oceanology, Engl. Transl., 31, 417423, 1991.

Savchuk, O., and F. Wulff, Biogeochemical transformations of nitrogen and phosphorus-A pelagic submodel for the Baltic Sea, Syst. Ecol. Contrib. 1, 50 pp., Stockholm Univ., Stockholm, Sweden, 1993.
Sharples, J., and P. Tett, Modelling the effect of physical variability on the midwater chlorophyll maximum, J. Mar. Res., 52, 219-238, 1994.

Sorokin, Y. I., The Black Sea, in Estuaries and Enclosed Seas. Ecosystem of the World, edited by B. H. Ketchum, pp. 253-292, Elsevier, New York, 1983.

Stramska, M., and T. D. Dickey, Modeling phytoplankton dynamics in the northeast Atlantic during the initiation of the spring bloom, $J$. Geophys. Res., 99, 10,241-10,254, 1994.

Sur, H. I., E. Ozsoy, and U. Unluata, Boundary current instabilities, upwelling, shelf mixing and eutrophication processes in the Black Sea, Prog. Oceanogr., 33, 249-302, 1994.

Totterdell, I. J., R. A. Armstrong, H. Drange, J. S. Parslow, T. M. Powell, and A. H. Taylor, Trophic resolution, in Towards a Model of Ocean Biogeochemical Processes, NATO ASI Ser., Ser. I, vol. 10, edited by G. T. Evans and M. J. R. Fasham, pp. 71-92, SpringerVerlag, New York, 1993.

Tugrul, S., and E. Morkoc, Transport and water quality modeling in the Bay of Izmit, Final Report, Turk. Sci. and Tech. Res. Counc., Gebze, Turkey, 1990.

Varela, R. A., A. Cruzado, J. Tintore, and E. G. Ladona, Modelling the deep-chlorophyll maximum: A coupled physical-biological approach, J. Mar. Res., 50, 441-463, 1992.

Vedernikov, V. I., and A. B. Demidov, Primary production and chlorophyll in the deep regions of the Black Sea, Oceanology, Engl. Transl., 33, 193-199, 1993.

Vidal, C. V., Bio-optical characteristics of the Mediterranean and the Black Sea, M.S. thesis, 134 pp., Inst. of Mar. Sci., Middle East Tech. Univ., Erdemli, Icel, Turkey, 1995.

Vinogradov, M. E., Long-term variability of the pelagic community structure in the open Black Sea, paper presented at the Problems of the Black Sea International Conference, NATO, Sevastopol, Ukraine, Nov. 10-15, 1992.

Vinogradov, M. Y., and E. A. Shushkina, Temporal changes in community structure in the open Black Sea, Oceanology, Engl. Transl., 32, 485-491, 1992.

Vladimirov, V. L., V. I. Mankovsky, M. V. Solovev, and A. V. Mishonov, Seasonal and long term variability of the Black Sea optical parameters, in Sensitivity of North Sea, Baltic Sea and Black Sea to Anthropogenic and Climatic Changes, NATO ASI Ser., Ser. C, edited by E. Ozsoy and A. Mikaelyan, Kluwer Acad., Norwell, Mass., in press, 1996.

Wroblewski, J., A model of phytoplankton bloom formation during variable Oregon upwelling, J. Mar. Res., 35, 357-394, 1977.

Zaitsev, Y. P., Recent changes in the trophic structure of the Black Sea, Fish. Oceanogr., 1, 180-189, 1992.

H. Ducklow, Virginia Institute of Marine Sciences, The College of William and Mary, P.O. Box 1346, Gloucester Point, VA 23062.

P. Malanotte-Rizzoli, Department of Earth, Atmospheric, and Planetary Sciences, Massachusetts Institute of Technology, 77 Massachusetts Avenue, Room 54-1416, Cambridge, MA 02139. (e-mail: rizzoli@ ocean.mit.edu)

N. P. Nezlin, P. P. Shirshov Institute of Oceanology, Russian Academy of Sciences, 23 Kraskova Street, Moscow, Russia, 117218.

T. Oguz, S. Tugrul, and U. Unluata, Institute of Marine Sciences, Middle East Technical University, P.O. Box 28, Erdemli, 33731 Icel, Turkey.

(Received September 1, 1995; accepted November 29, 1995.) 